\title{
Thermodynamic Database and the Phase Diagrams of the (U, Th, Pu)-X Binary Systems
}

\author{
C.P. Wang, Z.S. Li, W. Fang, and X.J. Liu
}

(Submitted April 3, 2009; in revised form May 11, 2009)

\begin{abstract}
A thermodynamic database for nuclear materials, including $\mathrm{U}-\mathrm{Th}, \mathrm{U}-\mathrm{Pu}, \mathrm{Th}-\mathrm{Pu}$, and (U, Th, Pu)-X (X = Al, Co, Cr, Cu, Fe, Ga, Mg, Mn, Mo, Nb, Ni, Si, Ta, W, Zr) binary system has been developed by the Calculation of Phase Diagrams (CALPHAD) method. Thermodynamic parameters describing Gibbs free energies of different phases have been evaluated by optimizing experimental data on phase equilibria and thermodynamic properties. The present thermodynamic database can provide much-needed information such as stable and metastable phase equilibria, phase fractions, and various thermodynamic quantities that is important to the design of nuclear materials. This database is also an essential starting point to construct thermodynamic databases for the multicomponent systems.
\end{abstract}

Keywords nuclear reactor materials, phase diagrams, thermodynamic modeling, thermodynamic properties

\section{Introduction}

With ever increasing global demands for energy and rapid depletion of fossil fuel, nuclear energy will become an important part of the global energy portfolio. ${ }^{[1]}$ To achieve nuclear energy's full potential, new nuclear materials need to be developed for new generations of reactors. The use of uranium (U), thorium $(\mathrm{Th})$, and plutonium $(\mathrm{Pu})$ in the production of nuclear energy has given considerable impetus to the investigation of nuclear materials in recent decades. The investigations of the $\mathrm{U}, \mathrm{Th}$, and $\mathrm{Pu}$ base alloys focus not only on the $\mathrm{U}, \mathrm{Th}$, and $\mathrm{Pu}$ compounds used in the fuels, but also on the structural materials and fission products of the $\mathrm{U}, \mathrm{Th}$, and $\mathrm{Pu}$ base alloys. ${ }^{[2-4]}$ In order to develop nuclear materials with better performance, a thermodynamic database of the $\mathrm{U}, \mathrm{Th}$, and $\mathrm{Pu}$ alloys for reliable predictions of liquidus, phase fraction, equilibrium,

This article is an invited paper selected from participants of the 14th National Conference and Multilateral Symposium on Phase Diagrams and Materials Design in honor of Prof. Zhanpeng Jin's 70th birthday, held November 3-5, 2008, in Changsha, China. The conference was organized by the Phase Diagrams Committee of the Chinese Physical Society with Drs. Huashan Liu and Libin Liu as the key organizers. Publication in Journal of Phase Equilibria and Diffusion was organized by J.-C. Zhao, The Ohio State University; Yong Du, Central South University; and Qing Chen, Thermo-Calc Software AB

C.P. Wang, Z.S. Li, W. Fang, and X.J. Liu, Department of Materials Science and Engineering, College of Materials, Xiamen University, Xiamen 361005, P.R. China and Research Center of Materials Design and Applications, Xiamen University, Xiamen 361005, P.R. China. Contact e-mail: 1xj@xmu.edu.cn. and nonequilibrium solidification behavior in multicomponent system is highly desirable.

The objective of the present study is to develop a thermodynamic database for the phase diagrams of the $\mathrm{U}$, $\mathrm{Th}$, and $\mathrm{Pu}$ containing systems including $(\mathrm{U}, \mathrm{Th}, \mathrm{Pu})-\mathrm{X}(\mathrm{U}$, Th, $\mathrm{Pu}, \mathrm{Al}, \mathrm{Co}, \mathrm{Cr}, \mathrm{Cu}, \mathrm{Fe}, \mathrm{Ga}, \mathrm{Mg}, \mathrm{Mn}, \mathrm{Mo}, \mathrm{Nb}, \mathrm{Ni}, \mathrm{Si}, \mathrm{Ta}$, $\mathrm{W}, \mathrm{Zr}$ ) binary systems using the Calculation of Phase Diagrams (CALPHAD) method.

\section{CALPHAD Method and Thermodynamic Models}

\subsection{CALPHAD Method}

The CALPHAD method is a powerful tool to reduce cost and time during development of materials. ${ }^{[5]}$ The optimization of the thermodynamic parameters of various phases was performed using the PARROT module of the Thermo-Calc software package, which takes various types of experimental data for the optimization process. The experimental data on phase diagrams and thermodynamic properties were used as inputs to the program. A certain weight was given according to the importance of the data, which was changed by trial and error during the assessments until most experimental data were reproduced within the expected uncertainty limits. The thermodynamic database is developed from the assessed parameters. This database consists of 149 phases, which include 131 intermetallic phases, 16 solution phases, L and gas. The descriptions of thermodynamic models in the $\mathrm{U}, \mathrm{Th}$, and $\mathrm{Pu}$ containing binary systems are given as follows.

\subsection{Solution Phases}

The Gibbs free energies of solution phases in the (U, Th, $\mathrm{Pu}$ )-X binary systems are described by a subregular solution model using the Redlich-Kister formula. ${ }^{[6]}$ Gibbs free 
energy of a solution phase in the ( $\mathrm{U}, \mathrm{Th}, \mathrm{Pu})-\mathrm{X}$ binary system is expressed as:

$G_{\mathrm{m}}^{\phi}=\sum_{i}{ }^{0} G_{i}^{\phi} x_{i}+R T \sum_{i} x_{i} \ln x_{i}+{ }^{\mathrm{E}} G_{m}^{\phi}+{ }^{\mathrm{mg}} G^{\phi}$,

where $G_{i}^{\phi}$ is the molar Gibbs free energy of pure element $i$ with the structure $\phi$ in a nonmagnetic state, which is taken from the lattice stability values for pure elements compiled by Dinsdale, ${ }^{[7]}$ and the term ${ }^{\mathrm{E}} G^{\phi}$ is the excess free energy, which is expressed in the Redlich-Kister polynomial $^{[6]}$ as:

${ }^{\mathrm{E}} G_{\mathrm{m}}^{\phi}=x_{i} x_{j}\left({ }^{0} L_{i, j}^{\phi}+{ }^{1} L_{i, j}^{\phi}\left(x_{i}-x_{j}\right)+{ }^{2} L_{i, j}^{\phi}\left(x_{i}-x_{j}\right)^{2}+\cdots\right)$,

where ${ }^{\mathrm{m}} L_{i, j}^{\phi}$ is the interaction energy between $i$ and $j$ atoms, and is expressed as:

${ }^{\mathrm{m}} L_{i, j}^{\phi}=a+b T+c T \ln (T)$,

the parameters of $a, b$, and $c$ are evaluated based on the experimental data. The term ${ }^{\mathrm{mg}} G^{\phi}$ is the magnetic contribution to the Gibbs free energies for the fcc, bcc, and hcp phases in the (U, Th, Pu)-X $(\mathrm{X}=\mathrm{Co}, \mathrm{Cr}, \mathrm{Fe}, \mathrm{Mn}, \mathrm{Ni})$ systems, can be expressed as ${ }^{[8]}$.

${ }^{\mathrm{mg}} G^{\phi}=R T \ln \left(\beta^{\phi}+1\right) f\left(\tau^{\phi}\right)$,

where $\beta^{\phi}$ is a quantity related to the total magnetic entropy, which in most cases is set to the Bohr magnetic moment per mole of atoms; $\tau^{\phi}$ is defined as $T / T_{\mathrm{c}}^{\phi}$, and $T_{\mathrm{c}}^{\phi}$ is the critical temperature for magnetic ordering, $T_{\mathrm{c}}^{\phi}$ and $\beta^{\phi}$ are described by the following expression:

$T_{\mathrm{c}}^{\phi}={ }^{0} T_{\mathrm{c}, i}^{\phi} x_{i}+{ }^{0} T_{\mathrm{c}, j}^{\phi} x_{j}$,

$\beta^{\phi}={ }^{0} \beta_{i}^{\phi} x_{i}+{ }^{0} \beta_{j}^{\phi} x_{j}$,

where ${ }^{0} T_{\mathrm{c}, i}^{\phi}$ and ${ }^{0} T_{\mathrm{c}, j}^{\phi}$ are the curie temperatures for pure $i$ and $j(i=\mathrm{Co}, \mathrm{Cr}, \mathrm{Fe}, \mathrm{Mn}$, or $\mathrm{Ni}, j=\mathrm{U}$, Th, or $\mathrm{Pu})$ and ${ }^{0} \beta_{i}^{\phi}$ and ${ }^{0} \beta_{j}^{\phi}$ are the Bohr magnetic moments for $i$ and $j$, respectively. The polynomial $f\left(\tau^{\phi}\right)$ is expressed as:

$f\left(\tau^{\phi}\right)=1-\frac{1}{D}\left[\frac{79 \tau^{-1}}{140 \mathrm{P}}+\frac{474}{497}\left(\frac{1}{P}-1\right)\left(\frac{\tau^{3}}{6}+\frac{\tau^{9}}{135}+\frac{\tau^{15}}{600}\right)\right]$

for $\tau \leq 1$,

$f\left(\tau^{\phi}\right)=-\frac{1}{D}\left(\frac{\tau^{-5}}{10}+\frac{\tau^{-15}}{315}+\frac{\tau^{-25}}{1500}\right) \quad$ for $\tau>1$,

where $D=\frac{518}{1125}+\frac{11692}{15975}\left(\frac{1}{P}-1\right)$, and $P$ depending on the structure and is 0.4 for the bcc structure and 0.28 for the other structures.

\subsection{Stoichiometric Intermetallic Compounds}

The stoichiometric intermetallic compounds in some (U, $\mathrm{Th}, \mathrm{Pu}$ )-X binary systems, for example, in the U-Ga, U-Mn, $\mathrm{Pu}-\mathrm{Cu}$, and $\mathrm{Pu}-\mathrm{Mg}$ systems, are treated as a formula unit

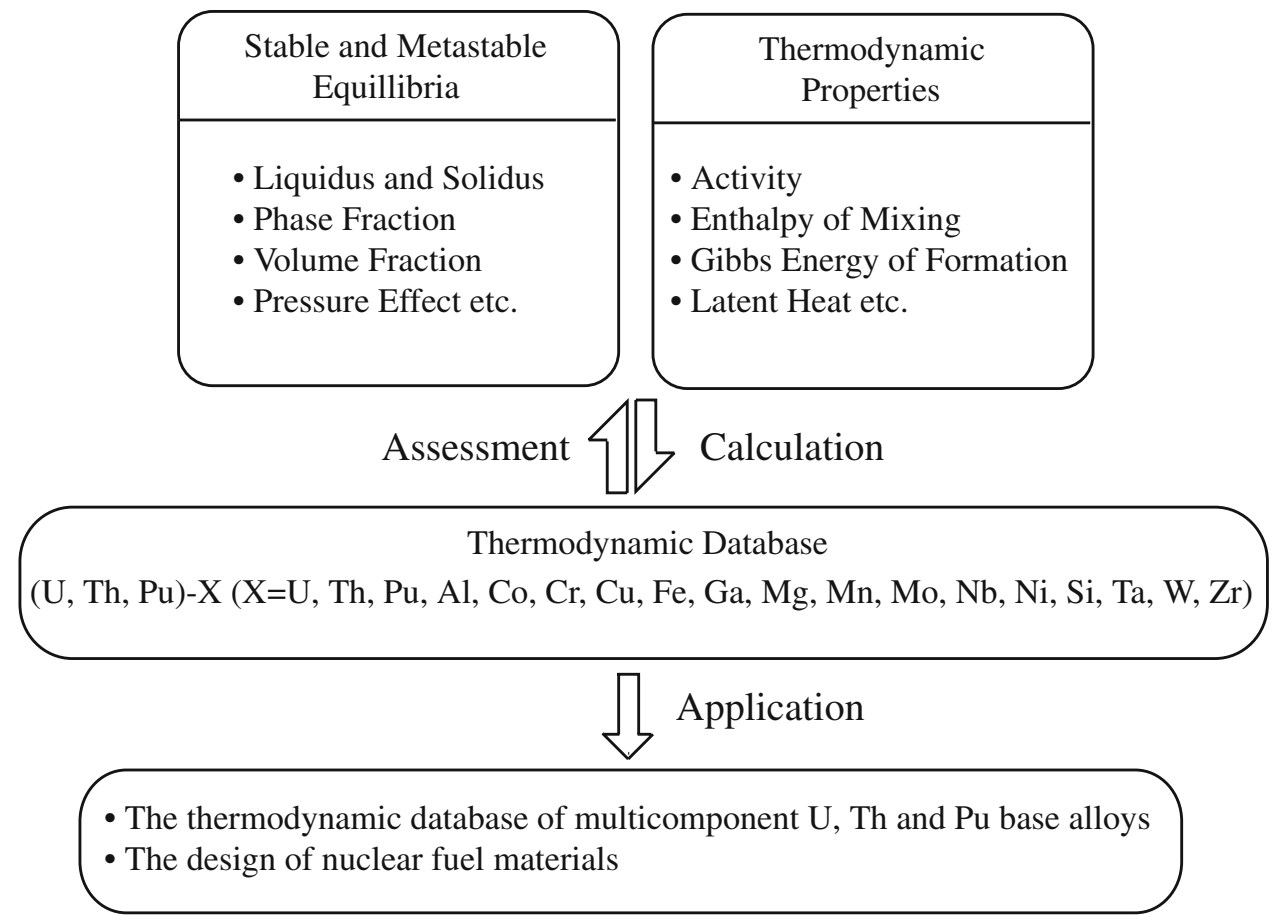

Fig. 1 Outline of the process for constructing the thermodynamic database 

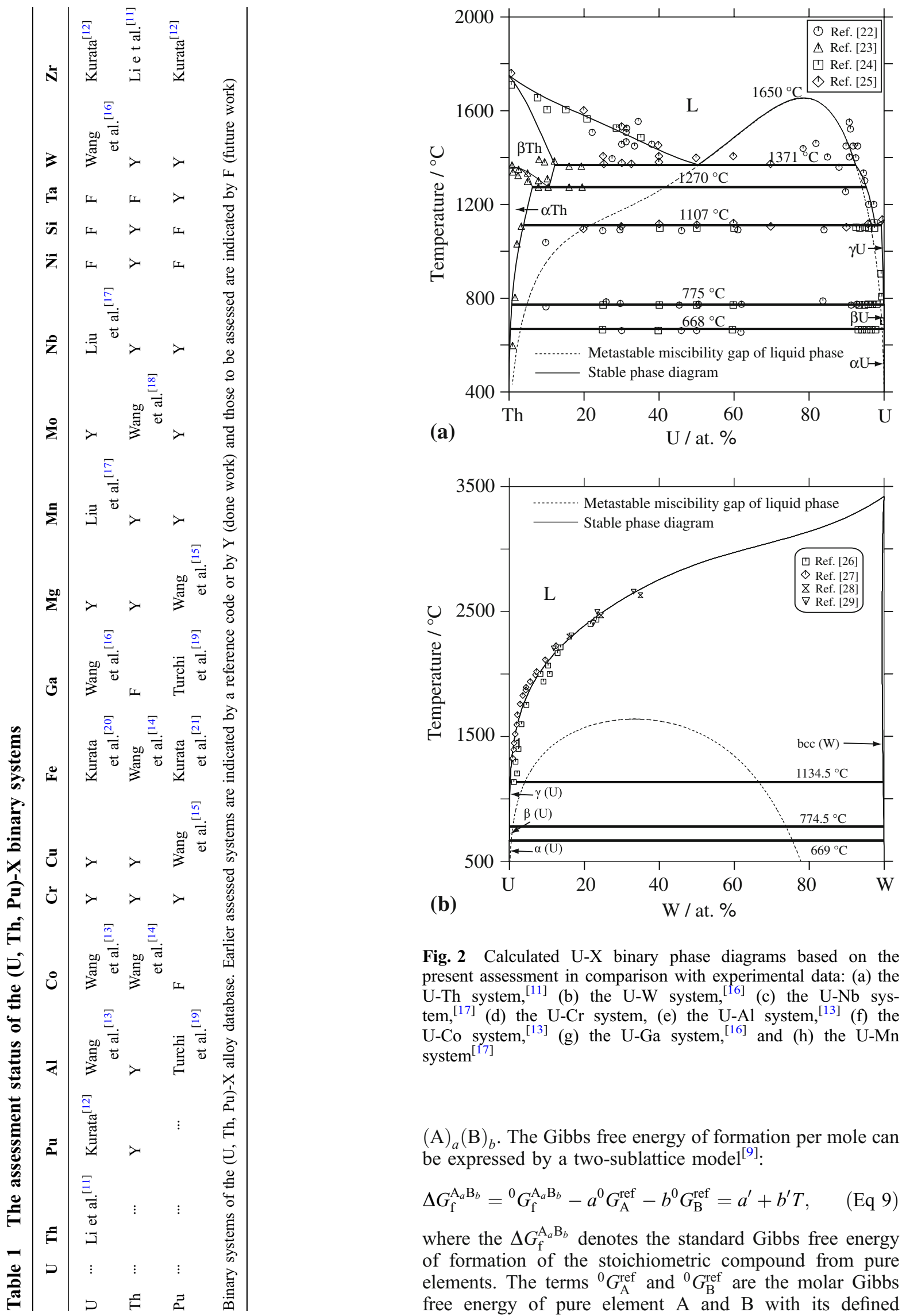

Fig. 2 Calculated U-X binary phase diagrams based on the present assessment in comparison with experimental data: (a) the U-Th system, ${ }^{[11]}$ (b) the U-W system, ${ }^{[16]}$ (c) the U-Nb system, ${ }^{[17]}$ (d) the U-Cr system, (e) the U-Al system, ${ }^{[13]}$ (f) the U-Co system, ${ }^{[13]}$ (g) the U-Ga system, ${ }^{[16]}$ and (h) the U-Mn system $^{[17]}$

$(\mathrm{A})_{a}(\mathrm{~B})_{b}$. The Gibbs free energy of formation per mole can be expressed by a two-sublattice model ${ }^{[9]}$ :

$\Delta G_{\mathrm{f}}^{\mathrm{A}_{a} \mathrm{~B}_{b}}={ }^{0} G_{\mathrm{f}}^{\mathrm{A}_{a} \mathrm{~B}_{b}}-a^{0} G_{\mathrm{A}}^{\mathrm{ref}}-b^{0} G_{\mathrm{B}}^{\mathrm{ref}}=a^{\prime}+b^{\prime} T$,

where the $\Delta G_{\mathrm{f}}^{\mathrm{A}_{a} \mathrm{~B}_{b}}$ denotes the standard Gibbs free energy of formation of the stoichiometric compound from pure elements. The terms ${ }^{0} G_{\mathrm{A}}^{\text {ref }}$ and ${ }^{0} G_{\mathrm{B}}^{\text {ref }}$ are the molar Gibbs free energy of pure element $\mathrm{A}$ and $\mathrm{B}$ with its defined 

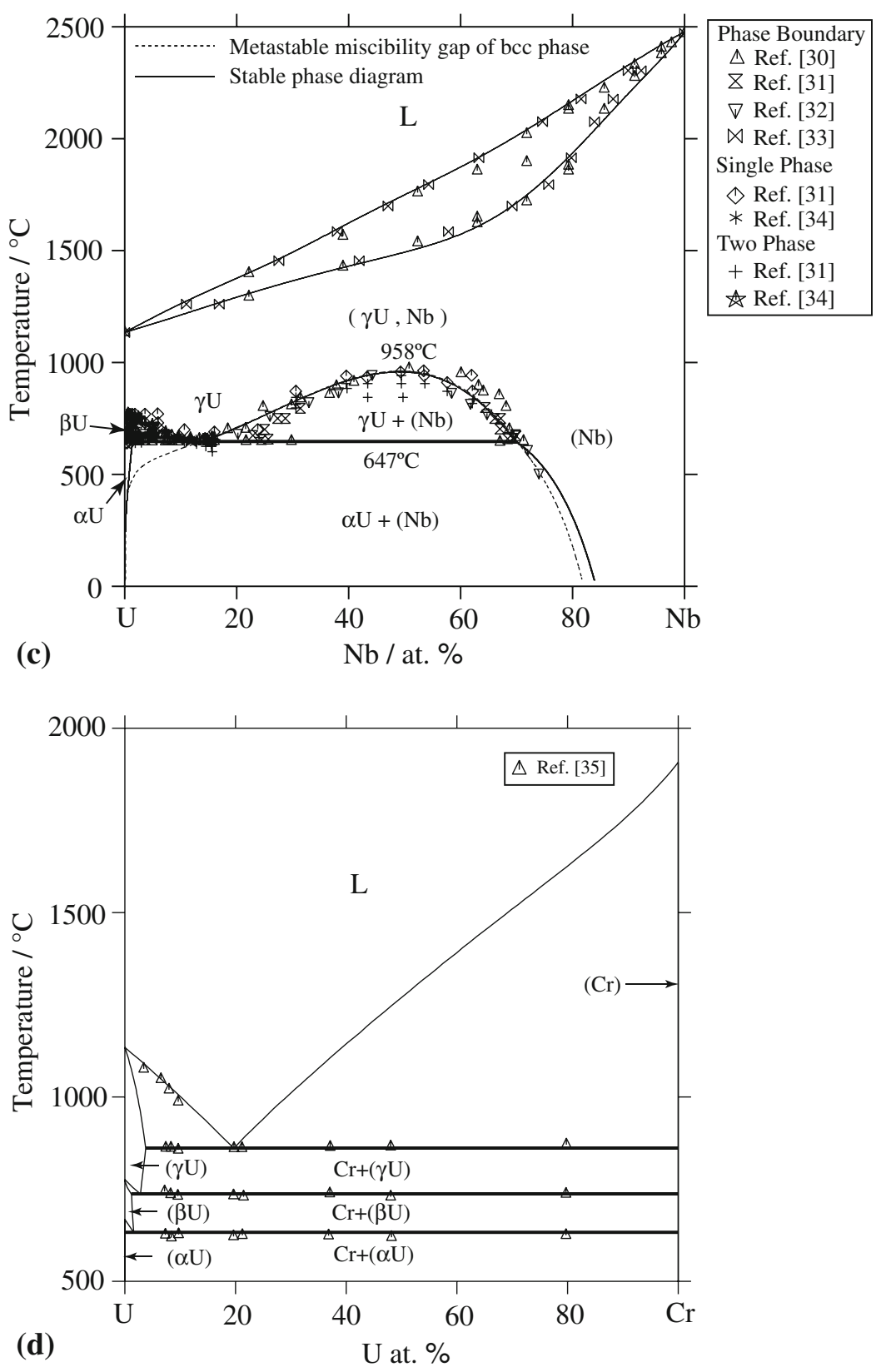

Fig. 2 Continued

reference structure in a nonmagnetic state. The parameters of $a^{\prime}$ and $b^{\prime}$ are to be evaluated in the present optimization.

\subsection{Nonstoichiometric Intermetallic Phases}

The Gibbs free energies of nonstoichiometric intermetallic phases in the (U, Th, Pu)-X systems, for example, the $\mathrm{UAl}_{4}$ phase in the $\mathrm{U}-\mathrm{Al}$ system and the $\mathrm{Co}_{2} \mathrm{U}$ phase in the U-Co system, are also described by a two-sublattice model. ${ }^{[9]}$ The Gibbs free energy of formation per mole of formula unit $(\mathrm{A}, \mathrm{B})_{a}(\mathrm{~A}, \mathrm{~B})_{b}$ can be expressed as the following equation referring to the pure elements in their nonmagnetic state:

$$
\begin{aligned}
& G_{\mathrm{m}}^{(\mathrm{A}, \mathrm{B})_{a}(\mathrm{~A}, \mathrm{~B})_{b}} \\
& =y_{\mathrm{A}}^{\mathrm{I}} y_{\mathrm{A}}^{\mathrm{II}} G_{\mathrm{A}: \mathrm{A}}+y_{\mathrm{A}}^{\mathrm{I}} y_{\mathrm{B}}^{\mathrm{II}} G_{\mathrm{A}: \mathrm{B}}+y_{\mathrm{B}}^{\mathrm{I}} y_{\mathrm{A}}^{\mathrm{II}} G_{\mathrm{B}: \mathrm{A}}+y_{\mathrm{B}}^{\mathrm{I}} y_{\mathrm{B}}^{\mathrm{II}} G_{\mathrm{B}: \mathrm{B}} \\
& +a R T\left(y_{\mathrm{A}}^{\mathrm{I}} \ln y_{\mathrm{A}}^{\mathrm{I}}+y_{\mathrm{B}}^{\mathrm{I}} \ln y_{\mathrm{B}}^{\mathrm{I}}\right)+b R T\left(y_{\mathrm{A}}^{\mathrm{II}} \ln y_{\mathrm{A}}^{\mathrm{II}}+y_{\mathrm{B}}^{\mathrm{II}} \ln y_{\mathrm{B}}^{\mathrm{II}}\right) \\
& +a y_{\mathrm{A}}^{\mathrm{I}} y_{\mathrm{B}}^{\mathrm{I}}\left[y_{\mathrm{A}}^{\mathrm{II}} \sum_{n}{ }^{n} L_{\mathrm{A}, \mathrm{B}: \mathrm{A}}\left(y_{\mathrm{A}}^{\mathrm{I}}-y_{\mathrm{B}}^{\mathrm{I}}\right)^{n}+y_{\mathrm{B}}^{\mathrm{II}} \sum_{n}{ }^{n} L_{\mathrm{A}, \mathrm{B}: \mathrm{B}}\left(y_{\mathrm{A}}^{\mathrm{I}}-y_{\mathrm{B}}^{\mathrm{I}}\right)^{n}\right] \\
& +b y_{\mathrm{A}}^{\mathrm{II}} y_{\mathrm{B}}^{\mathrm{II}}\left[y_{\mathrm{A}}^{\mathrm{I}} \sum_{n}{ }^{n} L_{\mathrm{A}: \mathrm{A}, \mathrm{B}}\left(y_{\mathrm{A}}^{\mathrm{II}}-y_{\mathrm{B}}^{\mathrm{II}}\right)^{n}+y_{\mathrm{B}}^{\mathrm{I}} \sum_{n}{ }^{n} L_{\mathrm{B}: \mathrm{A}, \mathrm{B}}\left(y_{\mathrm{A}}^{\mathrm{II}}-y_{\mathrm{B}}^{\mathrm{II}}\right)^{n}\right]
\end{aligned}
$$

where $y_{i}^{\mathrm{I}}$ and $y_{j}^{\mathrm{II}}$ are, respectively, the site fractions of component $i$ and $j(i, j=\mathrm{A}$ or $\mathrm{B})$ in sublattices $\mathrm{I}$ and 

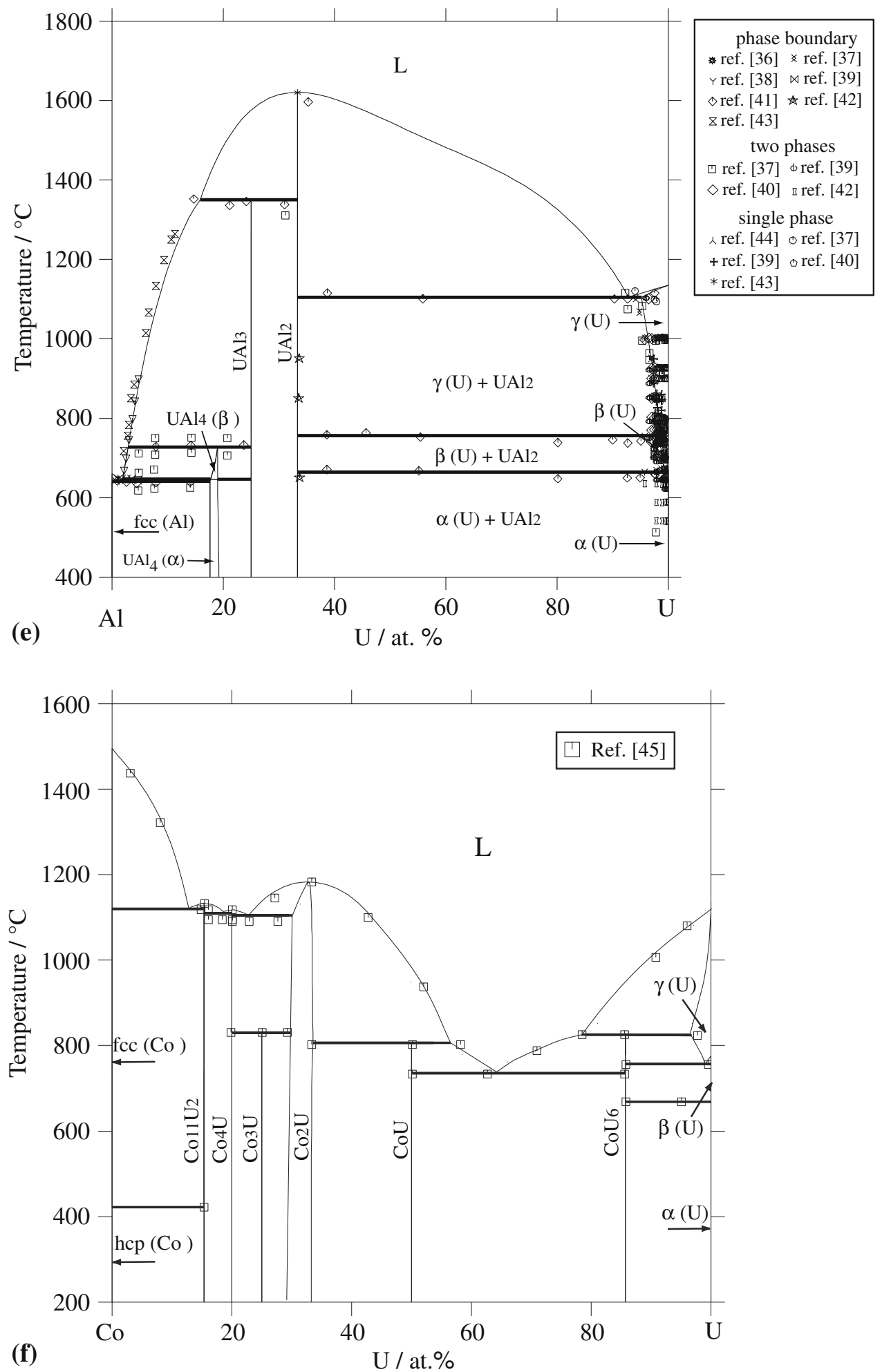

Fig. 2 Continued

II; the parameters $G_{i, j}$ represents the Gibbs free energy of the compound phase when the two sublattices are occupied by element $i$ or $j$, respectively; $L_{i: \mathrm{A}, \mathrm{B}}$ or $L_{\mathrm{A}, \mathrm{B}: j}$ is the interaction parameter between A and B in the second or first sublattice, when the first or second sublattice is occupied by element $i$ or $j$. 


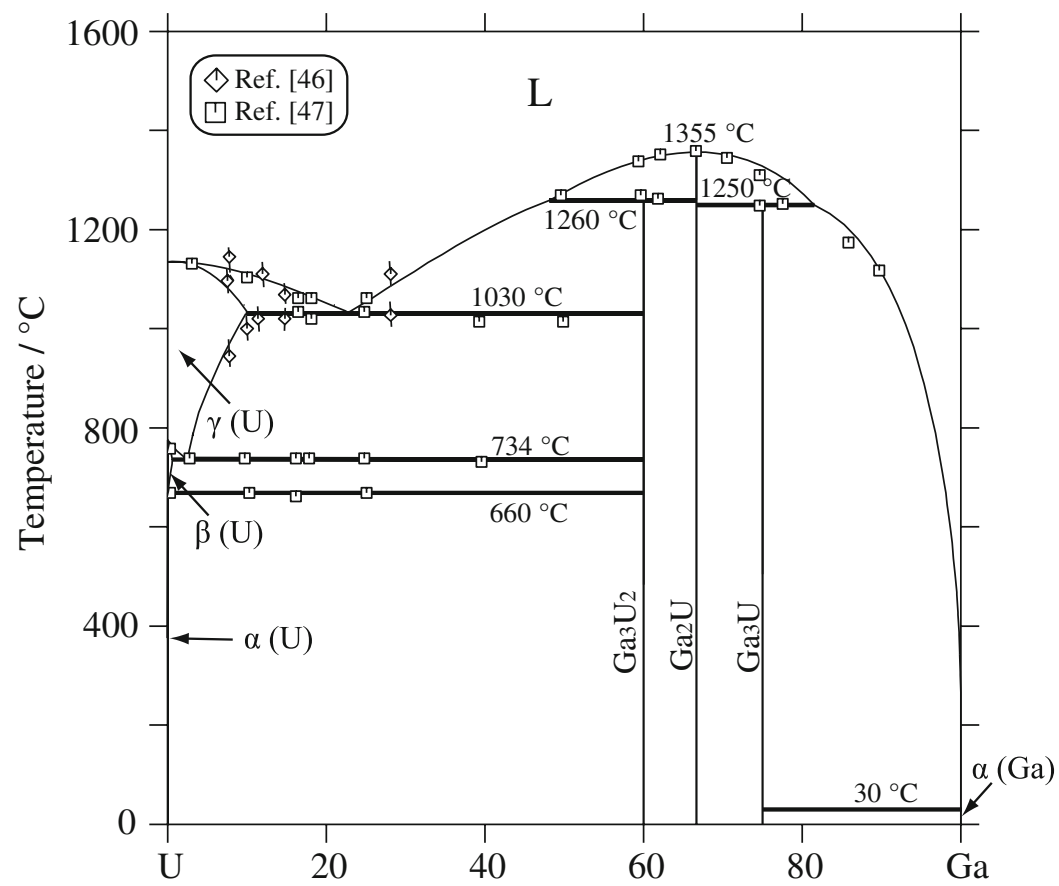

(g)

$\mathrm{Ga} /$ at. $\%$

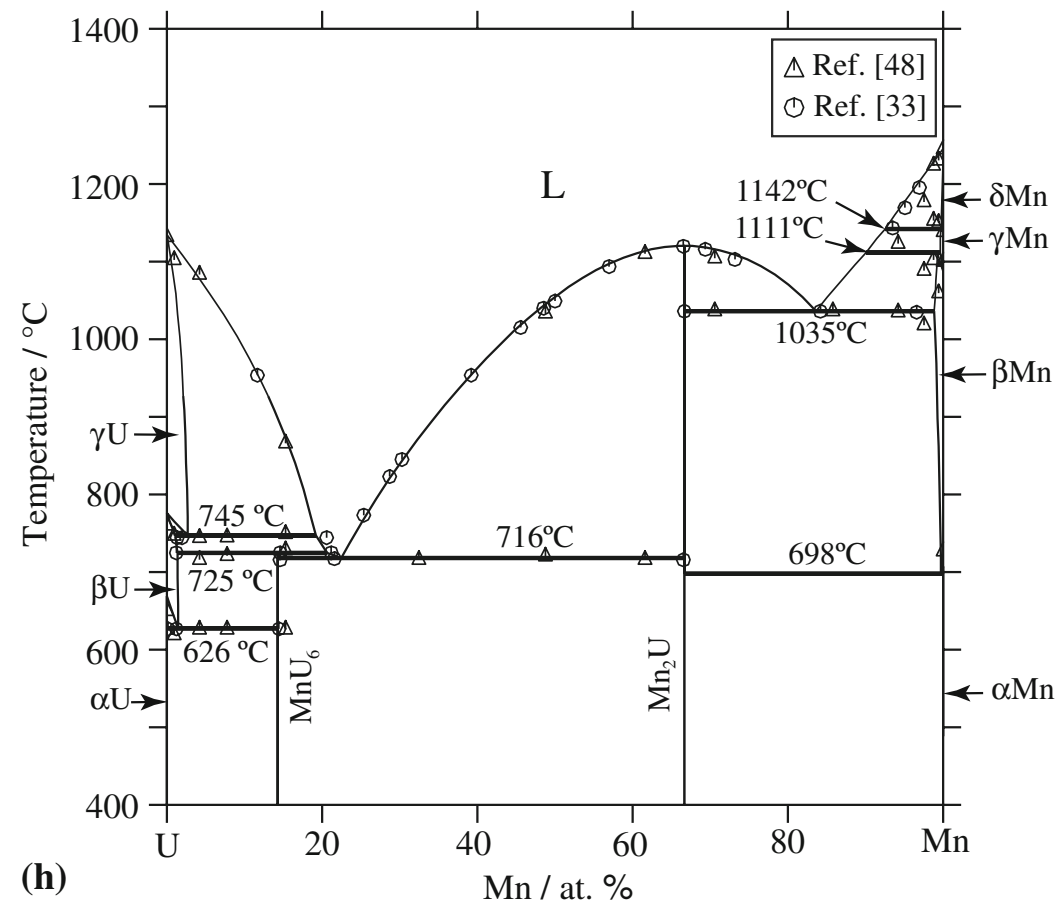

Fig. 2 Continued

\subsection{Gas Phases}

The gas phase in $\mathrm{Pu}-\mathrm{Mg}$ system is described as an ideal

$G^{\mathrm{gas}}=\sum_{i} x_{i}^{0} G_{i}^{\mathrm{gas}}+R T \sum_{i} x_{i} \ln x_{i}+R T \ln \left(\frac{P}{P_{0}}\right)$, mixture containing the gaseous species $\mathrm{Mg}, \mathrm{Mg}_{2}$, and $\mathrm{Pu}$. The Gibbs free energy of the species in the gas phase is given as: 
Basic and Applied Research: Section I
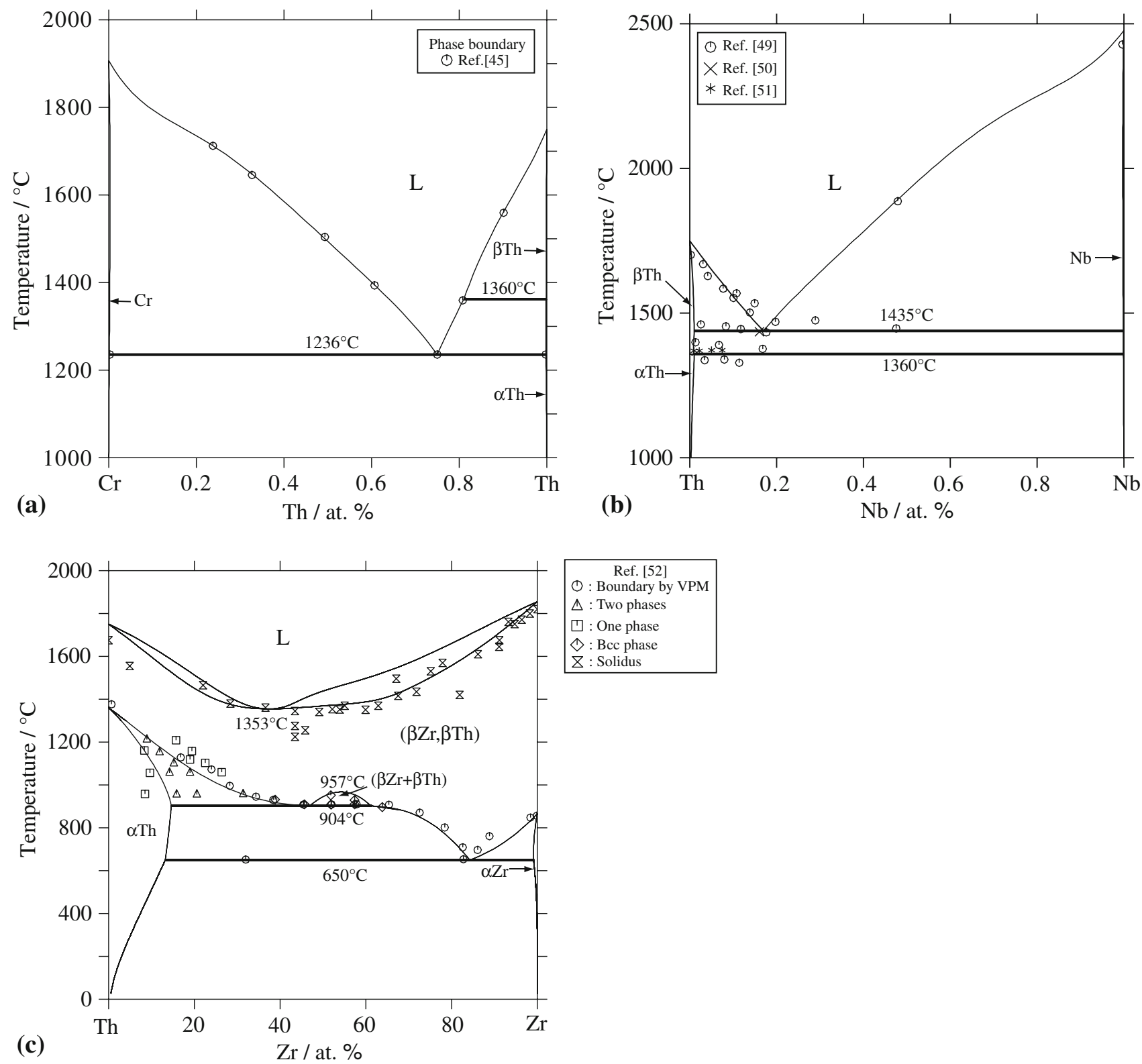

Fig. 3 Calculated Th-X binary phase diagrams based on the present assessment in comparison with experimental data: (a) the Th-Cr system, (b) the Th-Nb system, and (c) the Th-Zr system ${ }^{[11]}$ 
Section I: Basic and Applied Research
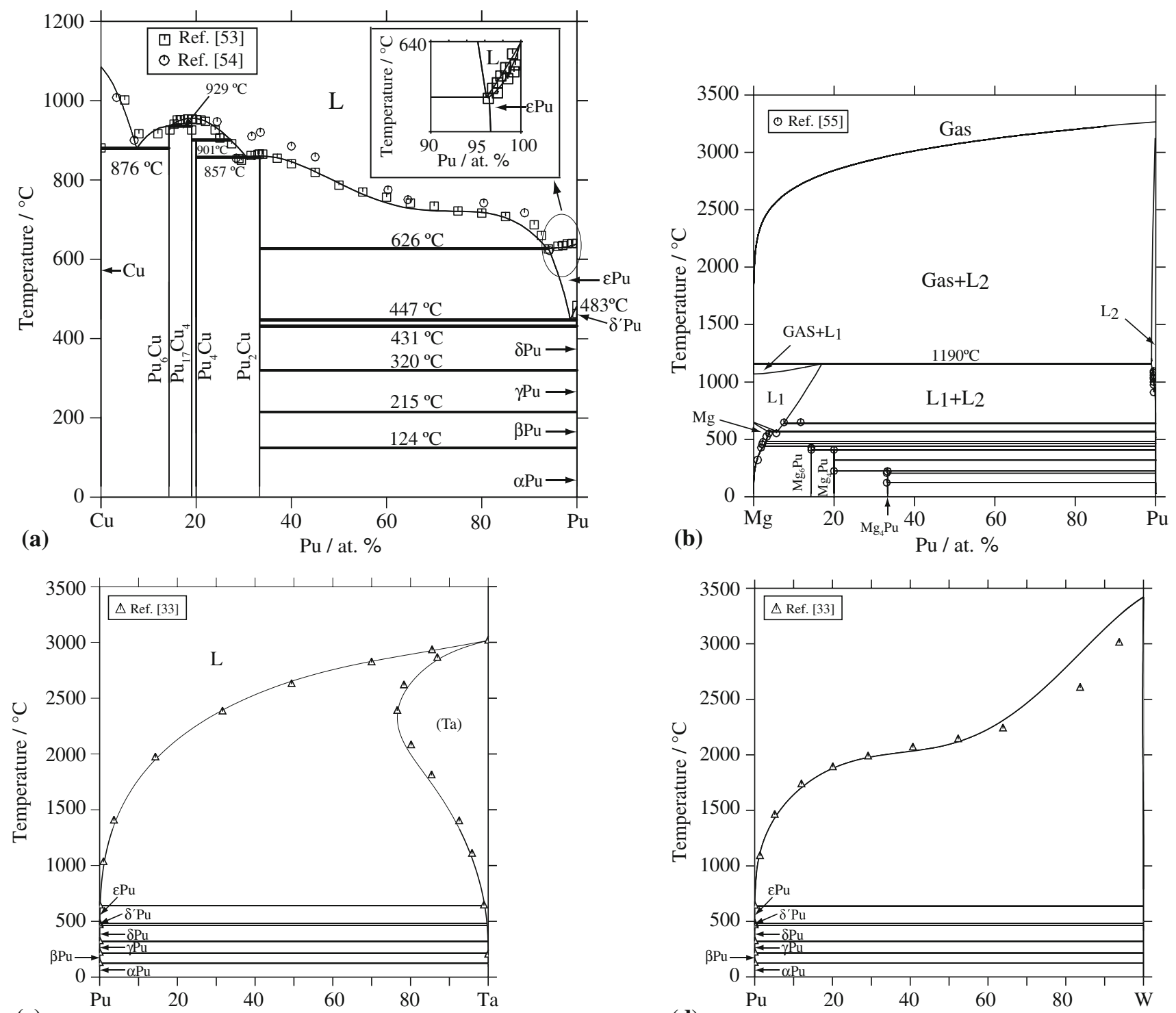

(c)

Ta / at. \%

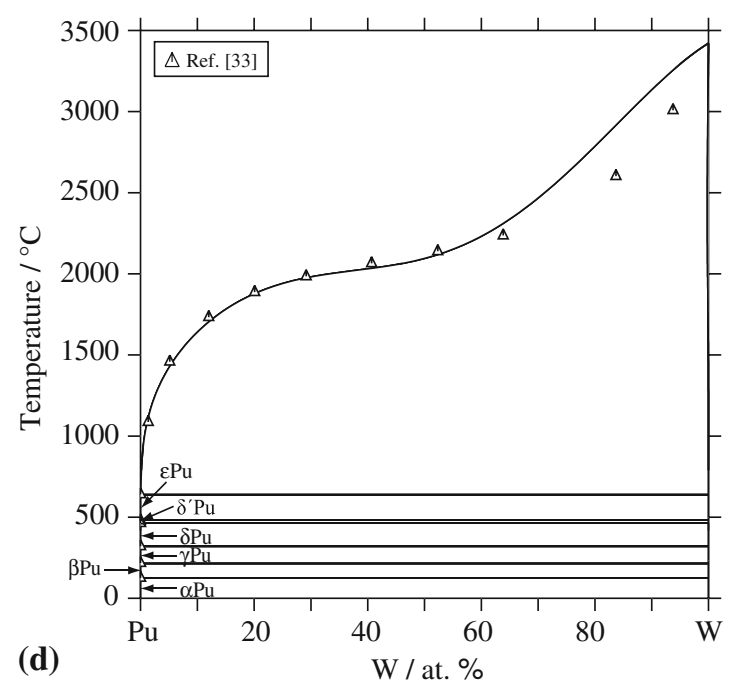

Fig. 4 Calculated $\mathrm{Pu}-\mathrm{X}$ binary phase diagrams based on the present assessment in comparison with experimental data: (a) the $\mathrm{Pu}-\mathrm{Cu}$ system, ${ }^{[15]}$ (b) the Pu-Mg system, ${ }^{[15]}$ (c) the Pu-Ta system, and (d) the Pu-W system 

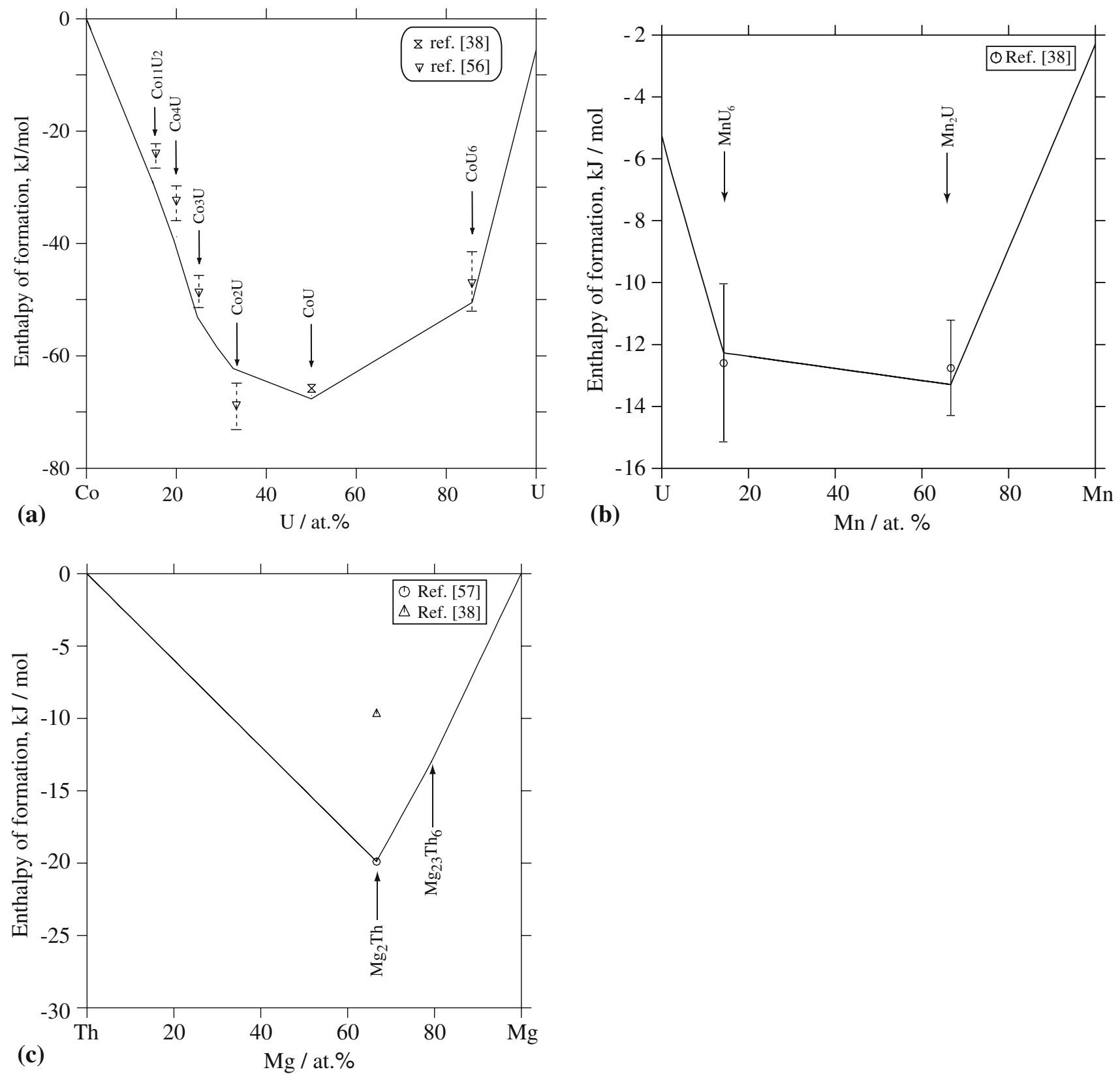

Fig. 5 Calculated enthalpies of formation of intermetallic compounds in several binary systems in comparison with experimental data: (a) the U-Co system at $727{ }^{\circ} \mathrm{C}^{[38,56]}$ (The reference states are the $\gamma$ (U) phase and the fcc (Co) phase), (b) the U-Mn system at $667{ }^{\circ} \mathrm{C}^{[38]}$ (The reference states are the $\gamma(\mathrm{U})$ phase and the $\beta(\mathrm{Mn})$ phase), and (c) the Th-Mg system at $700 \mathrm{~K}^{[38,57]}$ (The reference states are the $\alpha(\mathrm{Th})$ phase and the liquid ( $\mathrm{Mg}$ ) phase) 


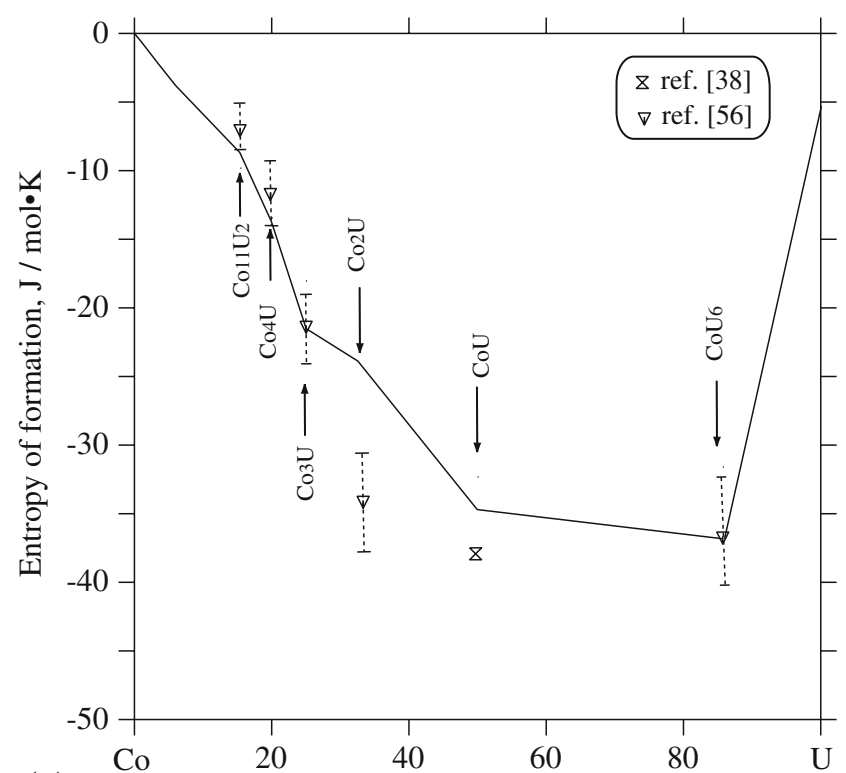

(a)

$\mathrm{U} /$ at. $\%$

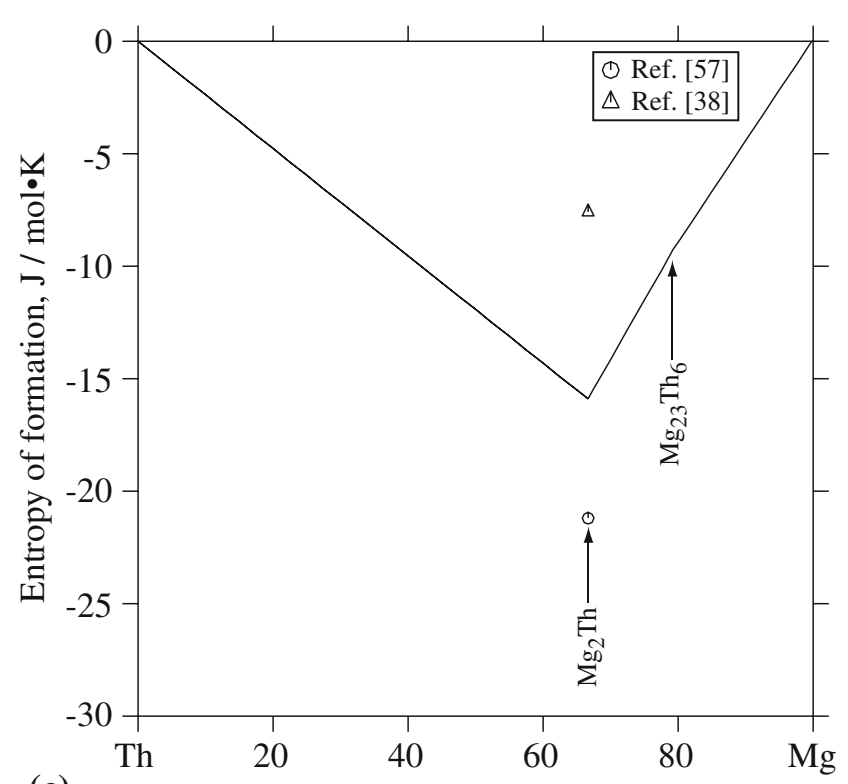

(c)

$\mathrm{Mg} /$ at. $\%$

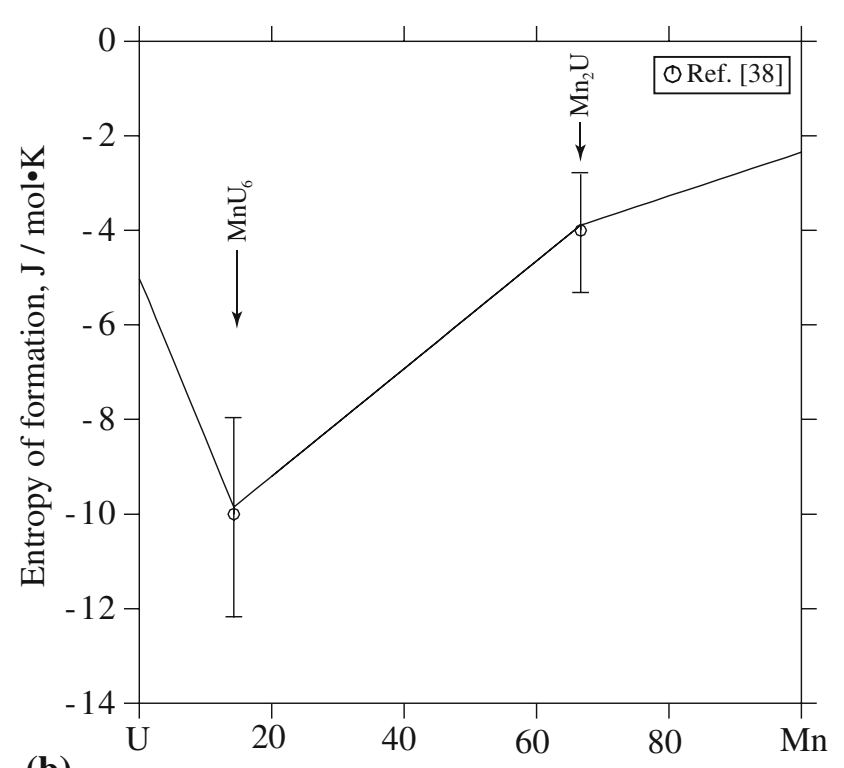

(b)

$\mathrm{Mn} /$ at. $\%$

Fig. 6 Calculated entropies of formation of intermetallic compounds in three binary systems in comparison with experimental data: (a) the U-Co system at $727{ }^{\circ} \mathrm{C}^{[38,56]}$ (The reference states are the $\gamma(\mathrm{U})$ phase and the fcc (Co) phase), (b) the U-Mn system at $667{ }^{\circ} \mathrm{C}^{[38]}$ (The reference states are the $\gamma(\mathrm{U})$ phase and the $\beta(\mathrm{Mn})$ phase), and (c) the Th-Mg system at $700 \mathrm{~K}^{[38,57]}$ (The reference states are the $\alpha(\mathrm{Th})$ phase and the liquid $(\mathrm{Mg})$ phase) 


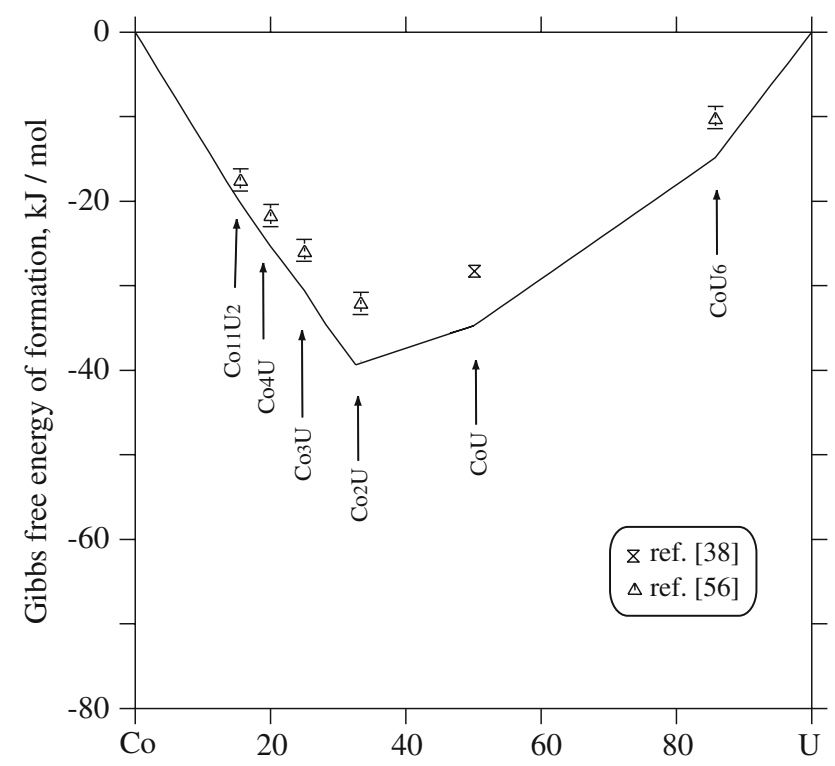

(a)

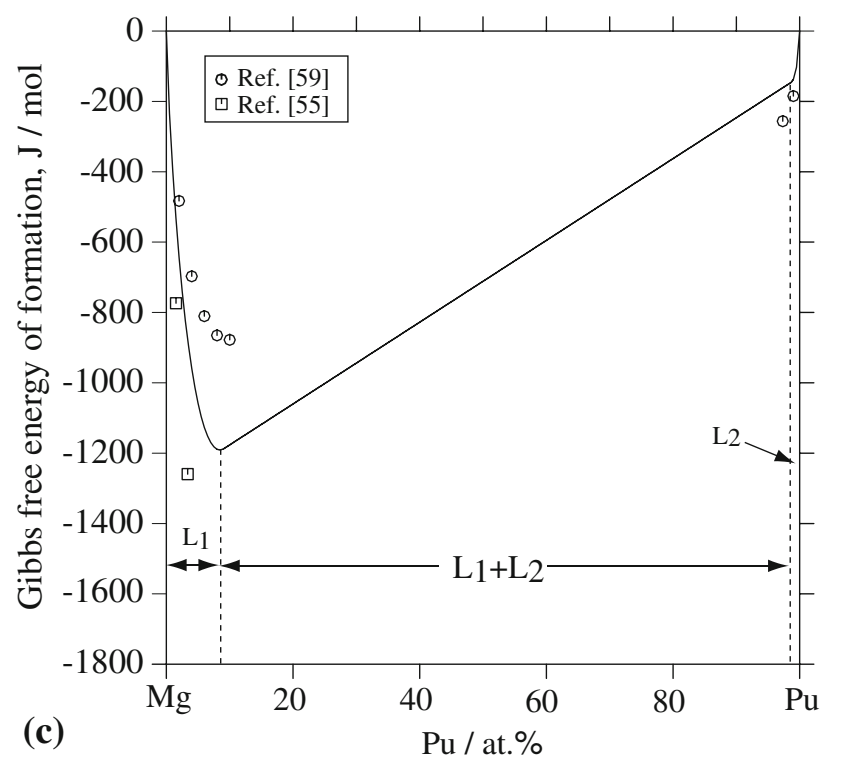

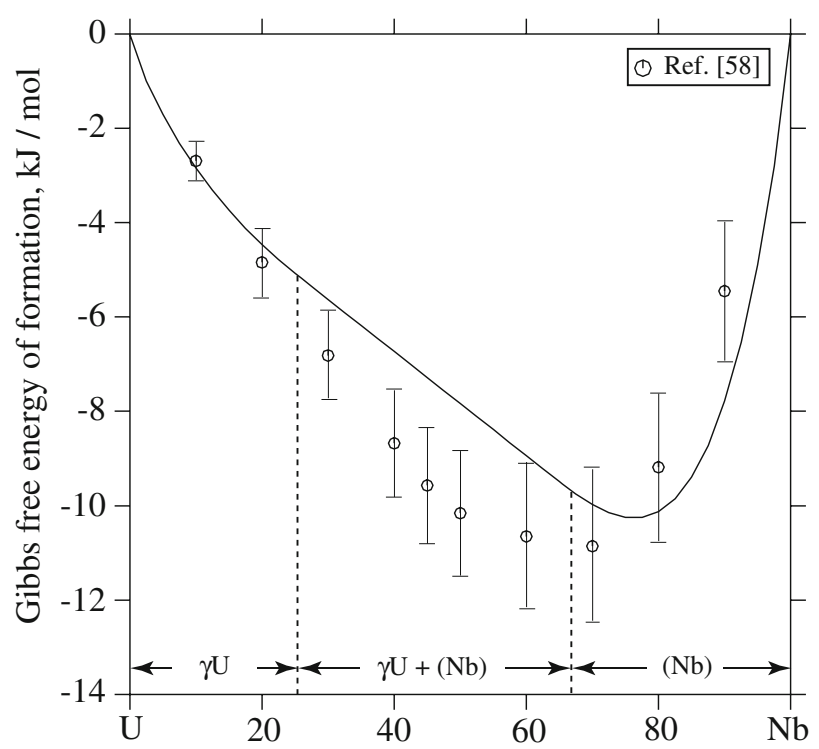

(b)

Fig. 7 Calculated Gibbs free energies of three binary systems in comparison with experimental data: (a) the U-Co system at $727{ }^{\circ} \mathrm{C}^{[38,56]}$ (The reference states are the $\gamma(\mathrm{U})$ phase and the fcc $(\mathrm{Co})$ phase), (b) the U-Nb system at $775{ }^{\circ} \mathrm{C}^{[58]}$ (The reference states are the $\gamma(\mathrm{U})$ phase and the bcc $(\mathrm{Nb})$ phase), and (c) the Pu-Mg system at $927^{\circ} \mathrm{C}^{[55,59]}$ (The reference states are the liquid $(\mathrm{Pu})$ phase and the liquid ( $\mathrm{Mg}$ ) phase) 


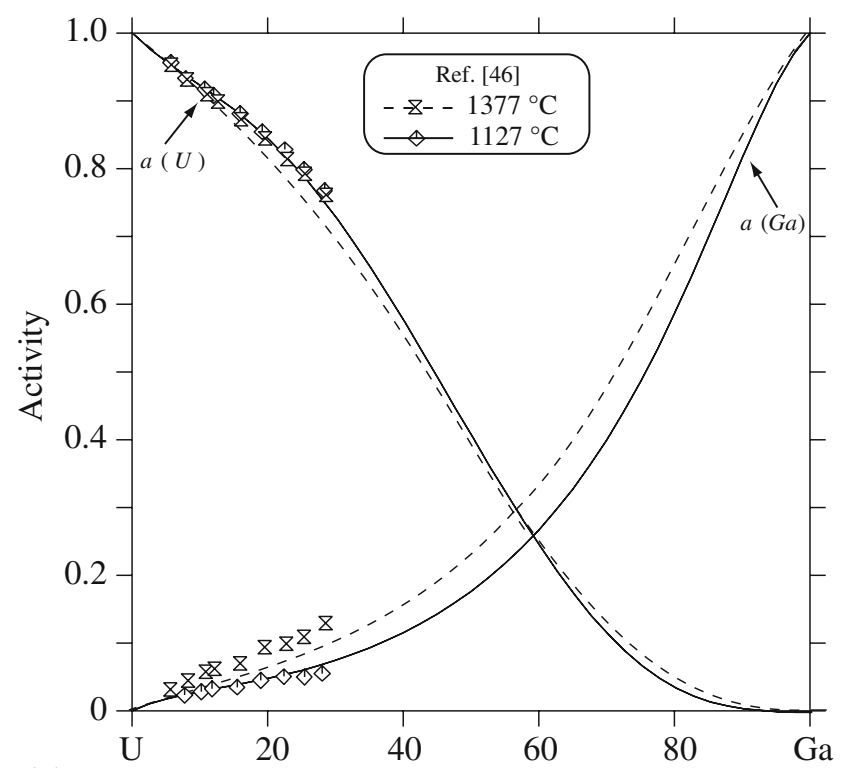

(a)

$\mathrm{Ga} /$ at. $\%$
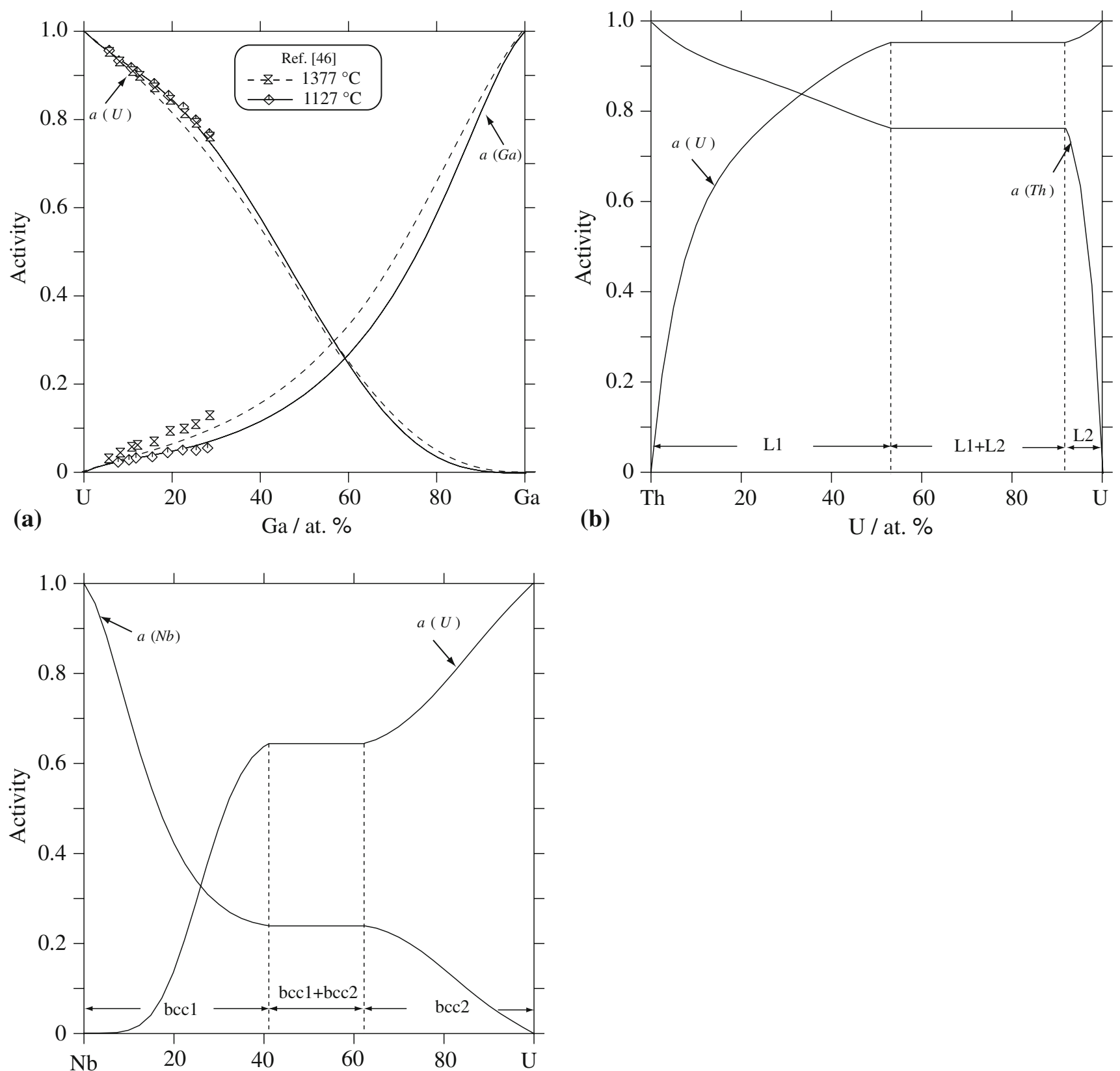

(c)

$\mathrm{U} /$ at. $\%$

Fig. 8 Calculated activities of three binary systems: (a) activities of $\mathrm{Ga}$ and $\mathrm{U}$ in the liquid phase at $1127{ }^{\circ} \mathrm{C}$ and $1377{ }^{\circ} \mathrm{C}$ in the $\mathrm{U}-\mathrm{Ga}$ system in comparison with experimental data (The reference states are the liquid (Ga) phase and the liquid (U) phase), (b) activities of $\mathrm{Th}$ and $\mathrm{U}$ in the liquid phase at $1400{ }^{\circ} \mathrm{C}$ in the U-Th system (The reference states are the liquid (Th) phase and the liquid (U) phase), and (c) activities of $\mathrm{Nb}$ and $\mathrm{U}$ in the bcc phase at $900{ }^{\circ} \mathrm{C}$ in the U-Nb system (The reference states are the bcc $(\mathrm{Nb})$ phase and the bcc (U) phase) 


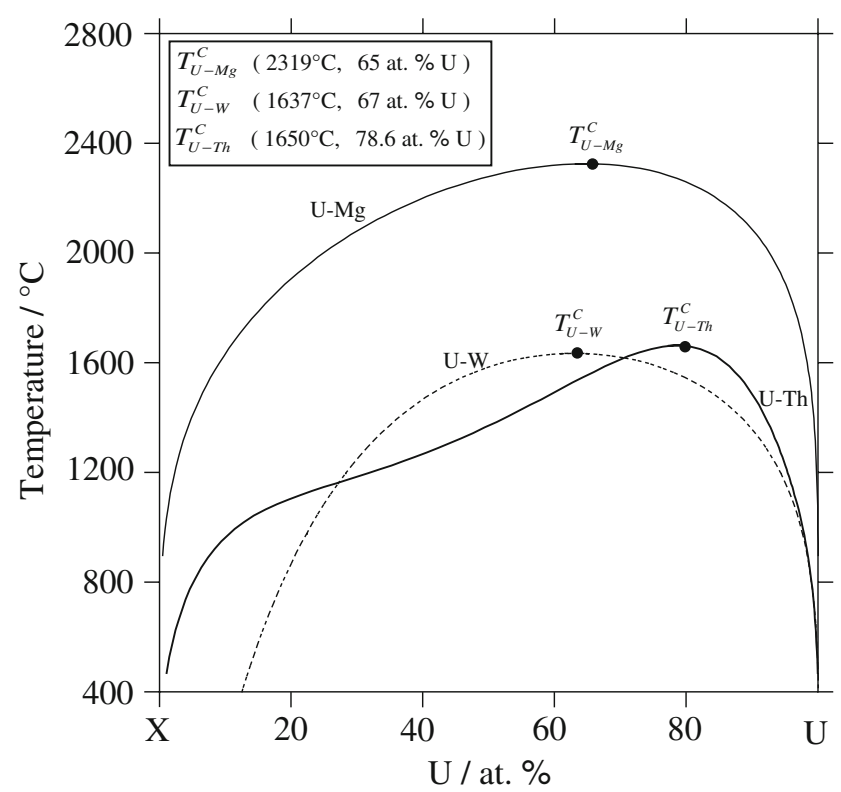

Fig. 9 Calculated miscibility gaps of the liquid phase in the U-X systems

species $i$, which is taken from the SGTE pure element database, ${ }^{[10]} R$ the gas constant, and $P_{0}$ the standard pressure at 1 bar.

\section{Thermodynamic Database and its Applications}

\subsection{Thermodynamic Database}

The thermodynamic optimization of phase equilibria was carried out using available experimental data. Figure 1 shows the scheme of the present thermodynamic database of the $\mathrm{U}, \mathrm{Th}$, and $\mathrm{Pu}$ base alloys, which provides information on phase diagrams and thermodynamic properties such as liquidus, solidus, mole fraction of constituent phases, activity, enthalpy of mixing, and Gibbs free energy of formation. These data are essential information for the calculation of multicomponent systems. Table 1 summarizes the assessment status of the (U, Th, Pu)-X $\left(\mathrm{X}=\mathrm{U}, \mathrm{Th},{ }^{[11]}\right.$ $\mathrm{Pu},{ }^{[12]} \mathrm{Al},{ }^{[13,19]} \mathrm{Co},{ }^{[13,14]} \mathrm{Cr}, \mathrm{Cu},{ }^{[15]} \mathrm{Fe}{ }^{[14,20,21]} \mathrm{Ga}{ }^{[16,19]}$ $\mathrm{Mg}^{[15]} \mathrm{Mn},{ }^{[17]} \mathrm{Mo},{ }^{[18]} \mathrm{Nb},{ }^{[17]} \mathrm{Ni}, \mathrm{Si}, \mathrm{Ta}, \mathrm{W},{ }^{[16]} \mathrm{Zr}^{[12,13]}$ ) binary systems.

\subsection{Calculation of Phase Equilibria}

Several phase diagrams of the (U, Th, Pu)-X binary systems were calculated using the present binary thermodynamic database for nuclear materials, as shown in Fig. 2, 3, 4. The metastable miscibility gap is presented as broken lines in Fig. 2(a) to (c). It can be seen that miscibility gaps of the liquid phase exist in the U-Th and U-W systems, and a miscibility gap of the bcc phase exists in the $\mathrm{U}-\mathrm{Nb}$ system. The complex phase diagrams of the U-Cr, U-Al, U-Co, U-Ga, U-Mn, Th-Cr, Th-Nb, Th-Zr, Pu-Cu, Pu-Mg,

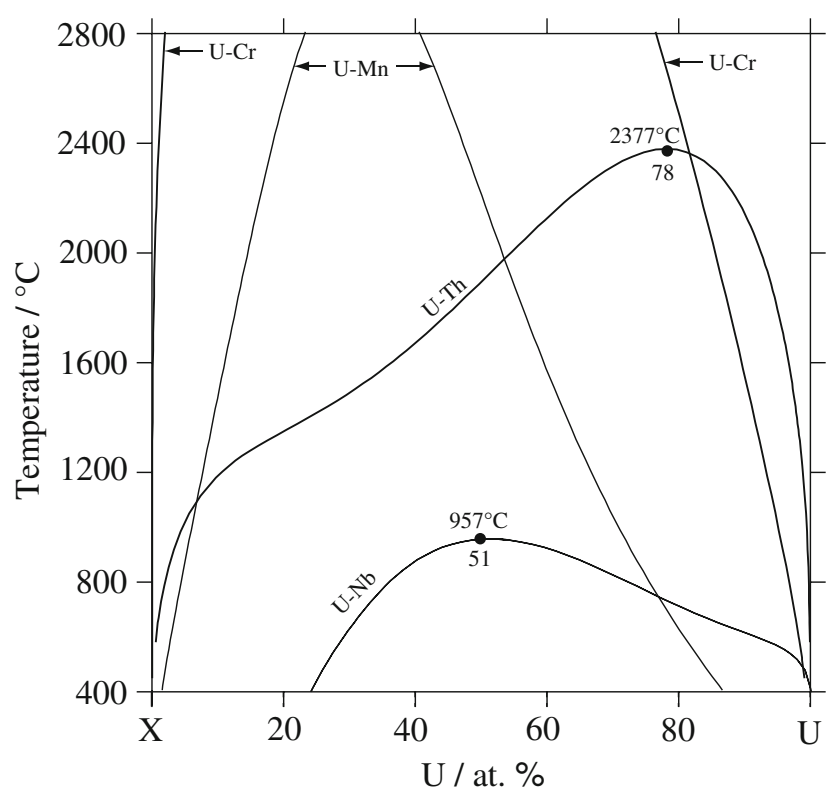

Fig. 10 Calculated miscibility gaps of bcc phase in the U-X systems

$\mathrm{Pu}-\mathrm{Ta}$, and $\mathrm{Pu}-\mathrm{W}$ systems with many intermetallic compounds and invariant reactions can also be calculated using this database, as shown in Fig. 2(d) to 4(d). The calculated results are in good agreement with the experimental data. ${ }^{[22-59]}$

\subsection{Calculation of Thermodynamic Properties}

As an example, the calculated thermodynamic properties in some $(\mathrm{U}, \mathrm{Th}, \mathrm{Pu})-\mathrm{X}$ binary systems are shown in Fig. 5 to 8. The calculated enthalpies and entropies of formation of intermetallic compounds in the U-Co, U-Mn, and Th-Mg systems at different temperatures are shown in Fig. 5 and 6. The Gibbs free energies of formation of the U-Co, U-Nb, and $\mathrm{Pu}-\mathrm{Mg}$ systems at different temperatures are shown in Fig. 7. The activity of the liquid phase in the U-Ga and U-Th system is shown in Fig. 8(a) and (b), and that of the bcc phase in the U-Nb system is shown in Fig. 8(c). And the activity of the liquid phase in the U-Ga system is compared with experimental data, which is in good agreement. From the calculated results, it is obvious that the thermodynamic parameters in the database can be used to calculate both phase diagrams and thermodynamic properties of different phases in the $(\mathrm{U}, \mathrm{Th}, \mathrm{Pu})-\mathrm{X}$ systems.

\subsection{Calculation of Metastable Phase Equilibria}

Based on the binary thermodynamic database of nuclear materials, metastable phase equilibria, such as the metastable miscibility gap of the liquid and the bcc phases can be estimated. For instance, the calculated metastable miscibility gaps of the liquid phase in the U-Th, U-W, and U-Mg binary systems are shown in Fig. 9, and the calculated metastable miscibility gaps of the bcc phase in the U-Cr, U-Nb, U-Mn, and U-Th binary systems are shown in Fig. 10. The 


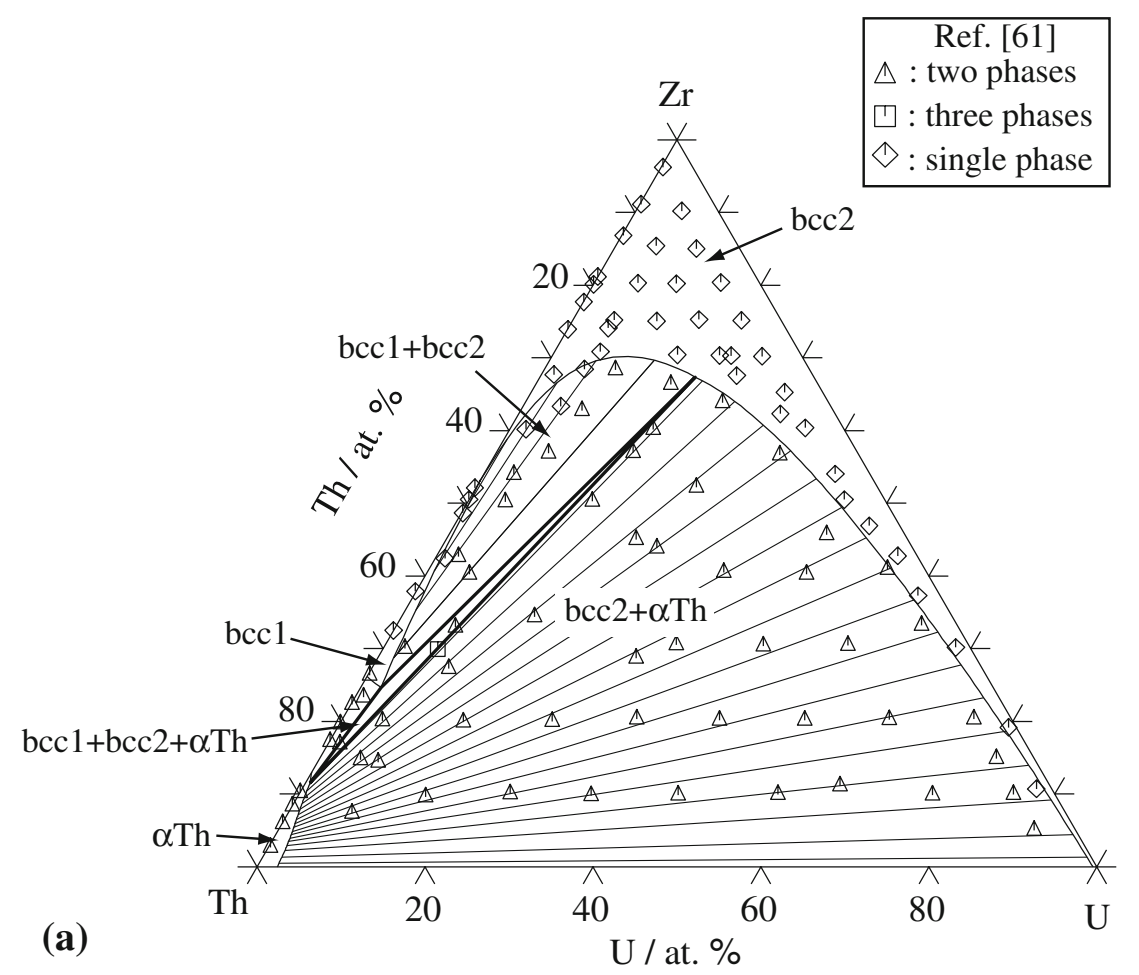

(b)

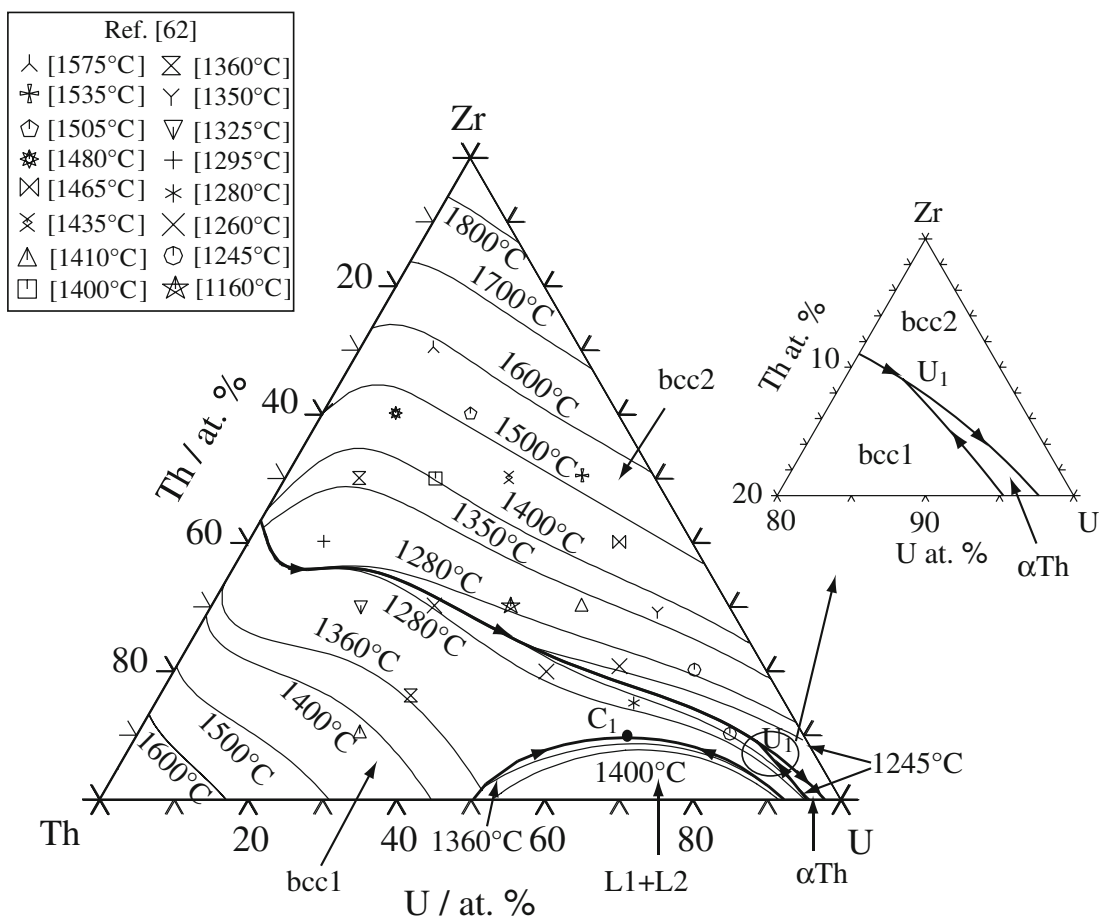

Fig. 11 Calculated ternary diagrams of the Th-U-Zr system: (a) isothermal section at $1000{ }^{\circ} \mathrm{C}$, (b) the liquidus projection, (c) isopleth at $U=1$ at.\%, and (d) isopleth at $U=4$ at. \%

calculated critical temperatures and compositions of the bcc miscibility gap in the U-Cr and U-Mn systems are $3072{ }^{\circ} \mathrm{C}$, 31.8 at. $\% \mathrm{U}$ and $4880{ }^{\circ} \mathrm{C}, 30.5$ at. $\% \mathrm{U}$, respectively. It can be seen that the critical temperature of the liquid miscibility gap in the U-Mg system is higher than that of U-Th or U-W system (e.g., $T_{\mathrm{U}-\mathrm{Mg}}^{\mathrm{C}}>T_{\mathrm{U}-\mathrm{Th}}^{\mathrm{C}}>T_{\mathrm{U}-\mathrm{W}}^{\mathrm{C}}$ ). Thus, it can be concluded that $\Delta H$ of the liquid phase in the U-Mg system is greater than that in the other systems, which is consistent 

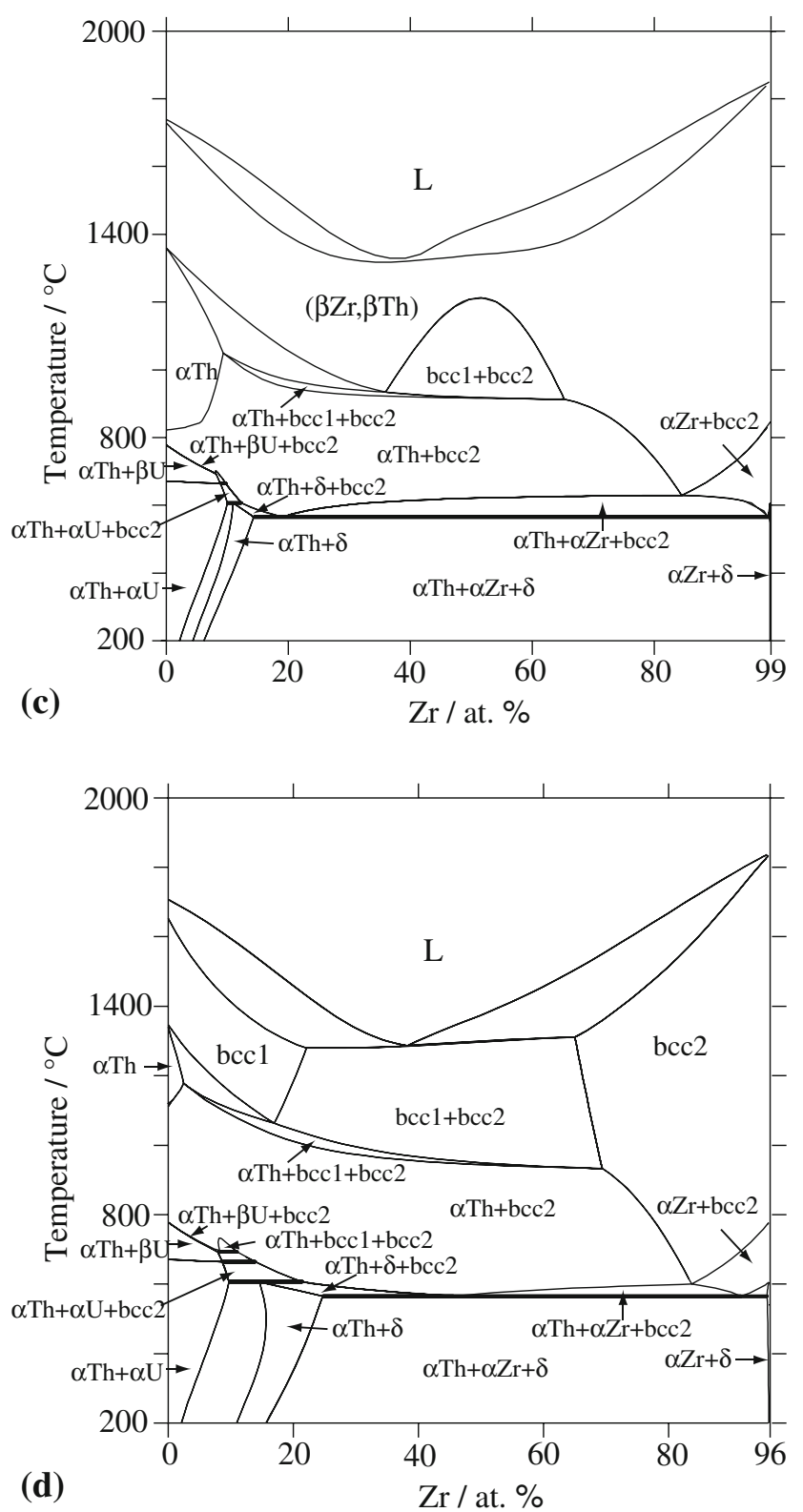

Fig. 11 Continued

with the data reported by Niessen et al. ${ }^{[60]}$ (e.g., $\Delta H_{\mathrm{U}-\mathrm{Mg}}$ $\left.(53 \mathrm{~kJ} / \mathrm{mol})>\Delta H_{\mathrm{U}-\mathrm{Th}}(19 \mathrm{~kJ} / \mathrm{mol})>\Delta H_{\mathrm{U}-\mathrm{W}}(4 \mathrm{~kJ} / \mathrm{mol})\right)$.

\subsection{Calculation of Ternary System Diagrams}

The present database can be used to estimate ternary phase diagrams when there are no ternary compounds and the solubility of a third element in the binary compounds is negligible. Figure 11(a) and (b) shows a calculated isothermal section and the liquidus projection of the Th- $\mathrm{U}-\mathrm{Zr}$ system in comparison with experimental data. ${ }^{[61,62]}$ The calculation isopleths at $1 \mathrm{U}$ at.\%, and $4 \mathrm{U}$ at. $\%$ of the Th-U-Zr system are shown in Fig. 11(c) and (d). The calculations show that the miscibility gap of the bcc phase in
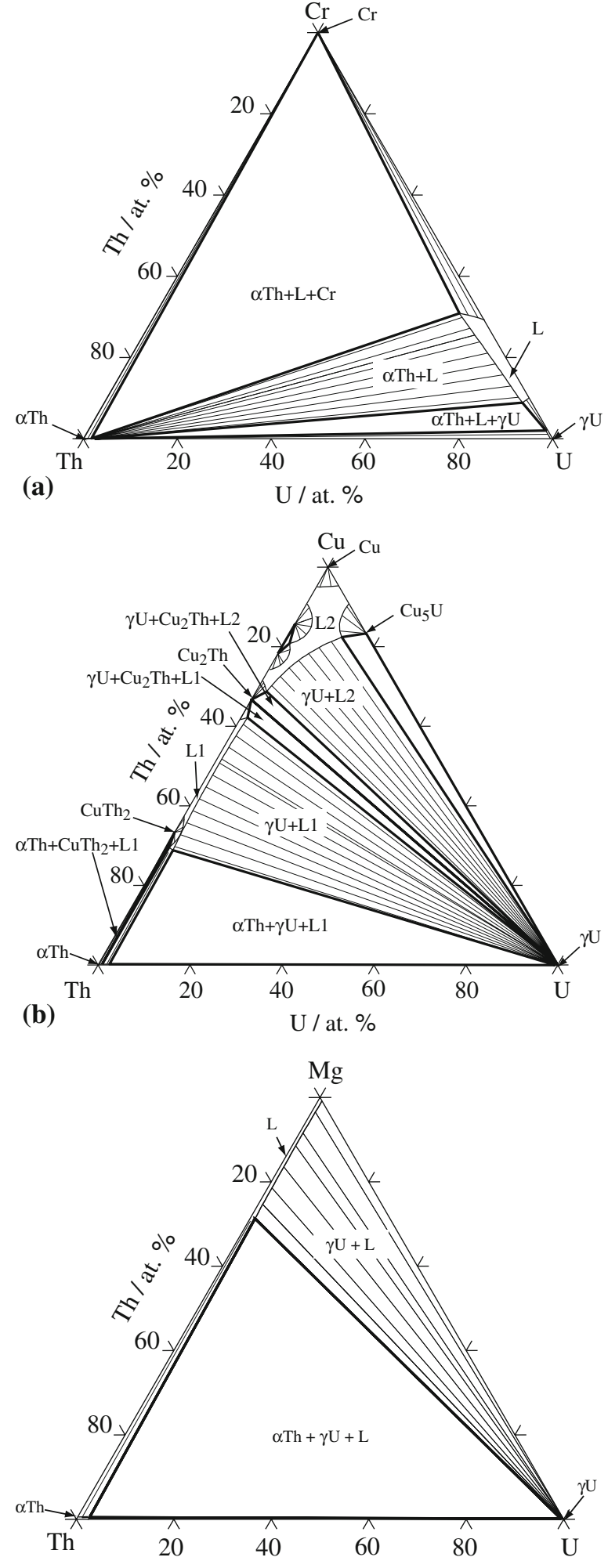

(c)

$\mathrm{U} /$ at. $\%$

Fig. 12 Calculated $1000{ }^{\circ} \mathrm{C}$ isothermal sections of the Th-U-X systems: (a) Th-U-Cr system, (b) the Th-U-Cu system, (c) the Th-U-Mg system, and (d) the Th-U-Mn system, and (e) the Th-U-Pu system 


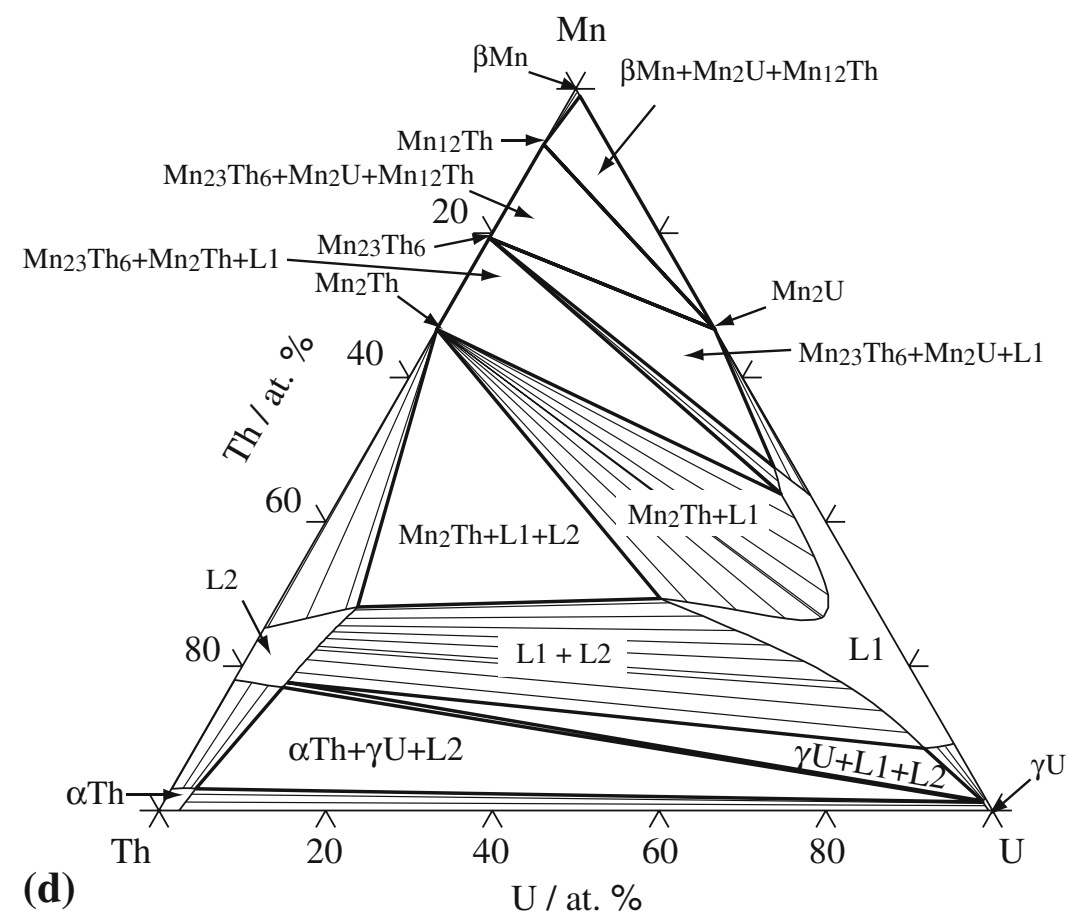

(d)

$\mathrm{U} /$ at. \%

(e)

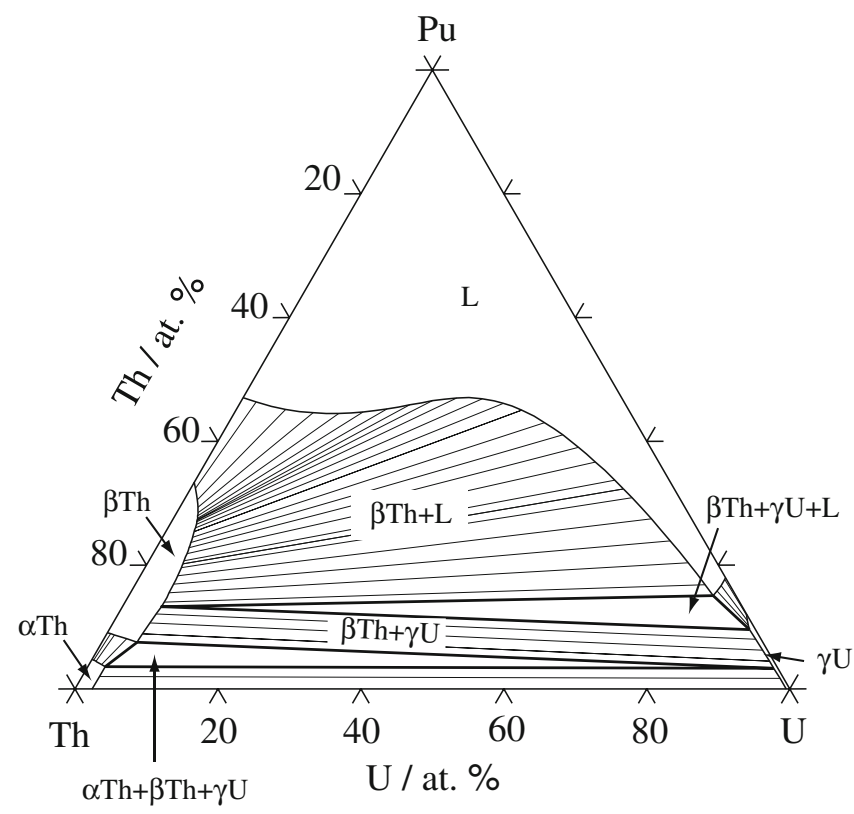

Fig. 12 Continued

the Th-U-Zr system becomes more stable as the content of $U$ increases. The calculated isothermal sections in the Th-U-X (X $=\mathrm{Cr}, \mathrm{Cu}, \mathrm{Mg}, \mathrm{Mn}, \mathrm{Pu})$ systems without any experimental data are shown in Fig. 12. These calculated results may provide information for the design of $\mathrm{U}, \mathrm{Th}$, and $\mathrm{Pu}$ base alloys. One should be cautioned that these predictions need to be validated before being used for practical applications since assumptions were made that there are no ternary compounds and little solubility of third elements in binary compounds.

\section{Summary}

A thermodynamic database for the $\mathrm{U}, \mathrm{Th}$, and $\mathrm{Pu}$ base alloy systems including $(\mathrm{U}, \mathrm{Th}, \mathrm{Pu})-\mathrm{X}(\mathrm{X}=\mathrm{U}, \mathrm{Th}, \mathrm{Pu}, \mathrm{Al}$, $\mathrm{Co}, \mathrm{Cr}, \mathrm{Cu}, \mathrm{Fe}, \mathrm{Ga}, \mathrm{Mg}, \mathrm{Mn}, \mathrm{Mo}, \mathrm{Nb}, \mathrm{Ni}, \mathrm{Si}, \mathrm{Ta}, \mathrm{W}$, and $\mathrm{Zr}$ ) binary systems was developed. This database can provide much-needed information such as phase diagrams, thermodynamic properties, and metastable phase equilibria for designing $\mathrm{U}$, Th, and $\mathrm{Pu}$ base alloys. 


\section{Acknowledgments}

This work was supported by the National Natural Science Foundation of China (Nos. 50425101 and 50771087).

\section{Open Access}

This article is distributed under the terms of the Creative Commons Attribution Noncommercial License which permits any noncommercial use, distribution, and reproduction in any medium, provided the original author(s) and source are credited.

\section{References}

1. D.J. Hill, Nuclear Energy for the Future, Nat. Mater, 2008, 7(9), p 680-682

2. C. Guéneau, S. Chatain, S. Gossé, C. Rado, O. Rapaud, J. Lechelle, J.C. Dumas, and C. Chatillon, A Thermodynamic Approach for Advanced Fuels of Gas-Cooled Reactors, J. Nucl. Mater, 2005, 344(1-3), p 191-197

3. R. Schmid-Fetzer, D. Andersson, P.Y. Chevalier, L. Eleno, O. Fabrichnaya, U.R. Kattner, B. Sundman, C. Wang, A. Watson, L. Zabdyr, and M. Zinkevich, Assessment Techniques, Database Design and Software Facilities for Thermodynamics and Diffusion, CALPHAD, 2007, 31(1), p 38-52

4. C. Degueldre and Ch. Guéneau, Introducing the Nuclear Material Challenges, J. Nucl. Mater., 2006, 352(1-3), p 1-5

5. L. Kaufman and H. Bernstein, Computer Calculation of Phase Diagrams, Academic Press, New York, 1970

6. O. Redlich and A.T. Kister, Algebraic Representation of Thermodynamic Properties and the Classification of Solutions, Industr. Eng. Chem., 1948, 40, p 345-348

7. A.T. Dinsdale, SGTE Data for Pure Elements, CALPHAD, 1991, 15, p 317-425

8. M. Hillert and M. Tsrl, A Model for Alloying in Ferromagnetic Metals, CALPHAD, 1978, 2, p 227-238

9. M. Hillert and L.I. Stafansson, The Regular Solution Model for Stoichiometric Phases and Ionic Melts, Acta Chem. Scand., 1970, 24, p 3618-3626

10. The SGTE Substance Database, version 1997, SGTE (Scientific Group Thermodata Europe), Grenoble, France, 1997

11. Z.S. Li, C.P. Wang, and X.J. Liu, Thermodynamic Modeling of the Th-U, Th-Zr and Th-U-Zr Systems, J. Alloys Comp., 2009, 476(1-2), p 193-198

12. M. Kurata, Thermodynamic Assessment of the $\mathrm{Pu}-\mathrm{U}, \mathrm{Pu}-\mathrm{Zr}$, and $\mathrm{Pu}-\mathrm{U}-\mathrm{Zr}$ Systems, CALPHAD, 1999, 23(3-4), p 305-337

13. J. Wang, C.P. Wang, and X.J. Liu, Thermodynamic Modeling of the Al-U and Co-U Systems, J. Nucl. Mater., 2008, 374(1-2), p 79-86

14. C.P. Wang, P. Yu, X.J. Liu, I. Ohnuma, R. Kainuma, and K. Ishida, Thermodynamic Assessment of the Co-Th and Fe-Th Systems, J. Alloys Comp., 2008, 475(1-2), p 150-156

15. C.P. Wang, W. Fang, X.J. Liu, and Z. S. Li, Thermodynamic Modeling of the $\mathrm{Mg}-\mathrm{Pu}$ and $\mathrm{Cu}-\mathrm{Pu}$ Systems, J. Nucl. Mater., in press

16. J. Wang, C.P. Wang, and X.J. Liu, Thermodynamic Calculation of Phase Equilibria of the U-Ga and U-W Systems, J. Nucl. Mater, 2008, 380(1-3), p 105-110

17. X.J. Liu, Z.S. Li, J. Wang, and C.P. Wang, Thermodynamic Modeling of the U-Mn and U-Nb Systems, J. Nucl. Mater., 2008, 380(1-3), p 99-104
18. C.P. Wang, Y.F. Li, X.J. Liu, I. Ohnuma, R. Kainuma, and K. Ishida, Thermodynamic Assessments of the $\mathrm{Cu}-\mathrm{Th}$ and Mo-Th Systems, J. Alloys Comp., 2008, 458(1-2), p 208-213

19. P.E.A. Turchi, L. Kaufman, S.H. Zhou, and Z.K. Liu, Thermostatics and Kinetics of Transformations in Pu-Based Alloys, J. Alloys Comp., 2007, 444-445, p 28-35

20. M. Kurata, T. Ogata, K. Nakamura, and T. Ogawa, Thermodynamic Assessment of the Fe-U, U-Zr and Fe-U-Zr Systems, J. Alloys Comp., 1998, 271-273, p 636-640

21. M. Kurata, K. Nakamura, and T. Ogata, Thermodynamic Evaluation of the Quaternary U-Pu-Zr-Fe System-Assessment of Cladding Temperature Limits of Metallic Fuel in a Fast Reactor, J. Nucl. Mater., 2001, 294(1-2), p 123-129

22. O.N. Carlson, "Some Studies on the Uranium-ThoriumZirconium Ternary Alloy System," USAEC Report AECU3206, 1950

23. G.G. Bentle, Study of the Thorium-Alloy System, Proc. UN Int. Conf. Peaceful Uses of Atomic Energy, Geneva, Vol. 6, 1958, p 156-161

24. J.R. Murray, The Uranium-Thorium System and Some Aspects of the Uranium-Thorium-Zirconium Alloy System, J. Inst. Met., 1958, 87, p 94-96

25. T.A. Badayeva and R.I. Kuznetsova, Solidus and Liquidus Surfaces of the Th-Zr-U Phase Diagram, Russ. Met., 1972, 1, p 196-200

26. C.H. Schramm, P. Gordon, and A.R. Kaufmann, The Alloy Systems Uranium-Tungsten, Uranium-Tantalum and Tungsten-Tantalum, J Met. Trans. AIME, 1950, 188, p 195-205

27. R.J. Ackermann and E.G. Rauh, Determination of Liquidus Curves for the Th-W, Th-Ta, Zr-W and Hf-W Systems: The Anomalous Behavior of Metallic Thorium, High Temp. Sci., 1972, 4, p 272-282

28. A. Saroja, Y.J. Bhatt, and S.P. Garg, Determination of Thermodynamic Properties of Liquid Th-Mo, U-Mo, Th-Ta, U-Ta, Th-W and U-W Alloys from Their Phase Diagrams, J. Less-Common Met., 1985, 114, p 291-297

29. M.S. Chandrasekharaiah, S.R. Dharwadhkar, and D. Das, High-Temperature Phase Diagrams of Re-U, Ta-U, and W-U Systems, Z. Metallkd, 1986, 77(8), p 509-514

30. B.A. Rogers, D.F. Atkins, E.J. Manthos, and M.E. Kirkpatrick, Uranium-Columbium Alloy Diagram, Trans. Metall. Soc. AIME, 1958, 212, p 387-393

31. P.C.L. Pfeil, J.D. Browne, and G.K. Williamson, The Uranium-Niobium Alloy System in the Solid State, J. Inst. Met., 1958, 87, p 204-208

32. O.S. Ivanov and G.I. Terekhov, Transformations of the $\gamma$-Solid Solution during Quenching and Tempering in the UraniumNiobium and Uranium-Niobium-Molybdenum Systems, U.S. Atomic Energy Commission, 1961, p 232-247

33. T.B. Massalski, P.R. Subramanian, H. Okamoto, and L. Kacprzak, Binary Alloy Phase Diagrams, ASM International, Materials Park, OH, 1990

34. C. Fizzotti and A. Maspereni, Effects of Heat Treatment on the Structure of Uranium-Rich U-Nb Alloys, Com. Naz. Energ. Nucl., 1966, RT1MET(66)-1, p 1-23, in Italian

35. A.H. Daane and A.S. Wilson, Uranium-Chromium System, Trans. AIME, 1955, 203, p 1219-1220

36. W.B. Pearson, A Handbook of Lattice Spacings and Structures of Metals and Alloys, Vol. 1, Pergamon Press, London, 1958

37. J.A. Straatman and N.F. Neumann, Equilibrium Structures in the High Uranium-Aluminum Alloy System, U.S. Atomic Energy Commission Report MCW-1488, 1964

38. P. Chiotti, V.V. Akhachinskji, I. Ansara, and M.H. Rand, The Chemical Thermodynamics of Actinide Elements and Compounds, International Atomic Energy Agency, Vienna, 1981 
39. D.K. Khakimova, Yu.S. Virgilev, and O.S. Ivanov, Stroenie $i$ Svoistva Splavov Urana, Toriya i Tsirkoniya, O.S. Ivanov, Ed., Gosatomizdat, Moscow, 1963, p 5-8, in Russian

40. P.R. Roy, Determination of $\alpha$-Aluminium Solid Solubility Limits in the Aluminium-Uranium and Aluminium-Plutonium Systems, J. Nucl. Mater., 1964, 11(1), p 59-66

41. J. Bellot, J.M. Henry, and G. Cabane, Contribution to the Study of Uranium Alloys by High Vacuum Differential Thermal Analysis, Mem. Sci. Rev. Met., 1959, 56, p 301-306

42. G. Petzow, S. Steeb, and I. Ellinghaus, The System $\mathrm{ZrAl}_{2}-$ $\mathrm{UAl}_{2}$, J. Nucl. Mater, 1961, 4(3), p 316-321

43. M.E. Kassner, P.H. Adler, and M.G. Adamson, Evaluation and Thermodynamic Analysis of Phase Equilibria in the U-Al System, J. Nucl. Mater., 1989, 167, p 160-168

44. P. Gordon and A.R. Kaufman, The Alloy Systems UraniumAluminum and Uranium-Iron, Trans. AIME., 1950, 188, p 182-194

45. K. Ishida and T. Nishizawa, Co-U, Desk Handbook - Phase Diagrams for Binary Alloys, H. Okamoto, Ed., ASM International, Materials Park, OH, 2000

46. P. Gardie, G. Bordier, J.J. Poupeau, and J. Le Ny, Thermodynamic Activity Measurements of U-Fe and U-Ga Alloys by Mass Spectrometry, J. Nucl. Mater., 1992, 189(1), p 85-96

47. K.H.J. Buschow, Phase Relationships and Magnetic Properties of Uranium-Gallium Compounds, J. Less-Common Met., 1973, 31(1), p 165-168

48. H.A. Wilhelm and O.N. Carlson, The Uranium-Manganese and Uranium-Copper Alloy Systems, Trans. ASM, 1950, 42, p 1311-1331

49. O.N. Carlson, J.M. Dickinson, H.E. Lunt, and H.A. Wilhelm, Thorium- Columbium and Thorium-Titanium Alloy Systems, Trans. AIME, 1956, 206, p 132-136

50. T.E. Pederson, M. Noack, and J.D. Verhoeven, Eutectic Alloys of Thorium-Niobium and Thorium-Titanium, J. Mater. Sci., 1980, 15, p 2115-2117

51. G.H. Bannister and J.R. Thomson, The Body-Centred-Cubic to Face-Centred-Cubic Phase Transformation in Thorium and
Some Thorium-Rich Alloys, J. Nucl. Mater, 1964, 12(1), p 16-23

52. E.D. Gibson, B.A. Loomis, and O.N. Carlson, ThoriumZirconium and Thorium-Hafnium Alloy Systems, Trans. ASM, 1958, 50, p 348-369

53. T.B. Rhinehammer, D.E. Etter, and L.V. Jones, The Plutonium-Copper Phase Diagram, Plutonium 1960, E. Grison, W.B.H. Lord, and R.D. Fowler, Ed., Cleaver-Hume Press Ltd., London, 1961, p 289-300

54. V.L. Kutaitsev, N.T. Chebotarev, I.G. Lebedev, M.A. Andrianov, V.N. Konev, and T.S. Menshikova, Phase Diagrams of Plutonium with the Metals of Groups II \& IVA, VIIIA and IB, Plutonium 1965, A.E. Kay and M.B. Waldron, Ed., Chapman and Hall, London, 1967, p 429-445

55. K.M. Axler, E.M. Foltyn, D.E. Peterson, R.I. Sheldon, and W.B. Hutchinson, The Plutonium-Magnesium System, J. Nucl. Mater, 1989, 161(2), p 132-139

56. V.A. Lebedev, V.I. Sal'nikov, I.F. Nichkov, and S.P. Raspopin, Thermodynamic Properties of Uranium-Aluminum Alloys, Soviet Atomic Energy, 1972, 32(2), p 129-132

57. D.B. Novotny and J.F. Smith, Thermodynamics of Formation of $\mathrm{ThMg}_{2}$, J. Inst. Met., 1963, 92, p 122-127

58. B. Sundman, B. Jansson, and J.O. Andersson, The ThermoCalc Databank System, CALPHAD, 1985, 9(2), p 153-190

59. W. Knoch, J.B. Knighton, and R.K. Steunenberg, Contribution to the Plutonium-Magnesium Phase Diagram, Nucl. Met., 1969, 15, p 535-546

60. A.K. Niessen, F.R. de Boer, R. Boom, P.F. Dechâtel, W.C.M. Mattens, and A.R. Miedema, Model Predictions for the Enthalpy of Formation of Transition Metal Alloys II, CALPHAD, 1983, 7(1), p 51-70

61. T.A. Badaeva and G.K. Alekseenko, Structure of Alloys of the Thorium-Zirconium-Uranium System, in Structure of Alloys in Some U and Th Systems, Gosatomizdat, Moscow, 1961, p 395415 , in Russian

62. T.A. Badaeva and R.I. Kuznetsova, Solidus and Liquids Surfaces of the Th-Zr-U Phase Diagram, Russian Metall., 1972, 1, p 139-142 